\title{
Article \\ The Rapid Chloride Migration Test in Assessing the Chloride Penetration Resistance of Normal and Lightweight Concrete
}

\author{
Jorge Pontes* $*$, José Alexandre Bogas, Sofia Real $\mathbb{1}$ and André Silva \\ CERIS, Instituto Superior Técnico, Universidade de Lisboa, Av. Rovisco Pais, 1049-001 Lisbon, Portugal; \\ jose.bogas@tecnico.ulisboa.pt (J.A.B.); sofia.real@tecnico.ulisboa.pt (S.R.); \\ andre.f.rosario.marcelino.silva@tecnico.ulisboa.pt (A.S.) \\ * Correspondence: jorge.pontes@tecnico.ulisboa.pt
}

check for updates

Citation: Pontes, J.; Bogas, J.A.; Real, S.; Silva, A. The Rapid Chloride Migration Test in Assessing the Chloride Penetration Resistance of Normal and Lightweight Concrete. Appl. Sci. 2021, 11, 7251. https:// doi.org/10.3390/app11167251

Academic Editor: Alexey Beskopylny

Received: 21 July 2021

Accepted: 4 August 2021

Published: 6 August 2021

Publisher's Note: MDPI stays neutral with regard to jurisdictional claims in published maps and institutional affiliations.

Copyright: (c) 2021 by the authors. Licensee MDPI, Basel, Switzerland. This article is an open access article distributed under the terms and conditions of the Creative Commons Attribution (CC BY) license (https:/ / creativecommons.org/licenses/by/ $4.0 /)$.

\begin{abstract}
Chloride-induced corrosion has been one of the main causes of reinforced concrete deterioration. One of the most used methods in assessing the chloride penetration resistance of concrete is the rapid chloride migration test (RCMT). This is an expeditious and simple method but may not be representative of the chloride transport behaviour of concrete in real environment. Other methods, like immersion (IT) and wetting-drying tests (WDT), allow for a more accurate approach to reality, but are laborious and very time-consuming. This paper aims to analyse the capacity of RCMT in assessing the chloride penetration resistance of common concrete produced with different types of aggregate (normal and lightweight) and paste composition (variable type of binder and water/binder ratio). To this end, the RCMT results were compared with those obtained from the same concretes under long-term IT and WDT. A reasonable correlation between the RCMT and diffusion tests was found, when slow-reactive supplementary materials or porous lightweight aggregates surrounded by weak pastes were not considered. A poorer correlation was found when concrete was exposed under wetting-drying conditions. Nevertheless, the RCMT was able to sort concretes in different classes of chloride penetration resistance under distinct exposure conditions, regardless of the type of aggregate and water/binder ratio.
\end{abstract}

Keywords: chloride diffusion; chloride migration; rapid chloride migration test; immersion test; wetting-drying test; normal weight concrete; lightweight concrete

\section{Introduction}

Reinforcement steel corrosion is widely acknowledged as the main degradation mechanism of reinforced concrete structures. This phenomenon occurs after the depassivation of the steel reinforcement, which, among others, can originate from chloride attack [1].

For a reliable and accurate prediction of the service life of concrete structures in marine exposure environments, the chloride-ion penetration needs to be perfectly understood and well simulated by representative expeditious methods for accessing the concrete resistance to chloride attack. However, the chloride-ion penetration in concrete is a complex phenomenon that involves a diverse set of transport mechanisms, namely diffusion, capillary absorption and permeation. Moreover, the chloride-ion penetration can also involve more than one of these mechanisms, besides physical and chemical interactions with the hydrated cement paste [2,3]. In general, this is simplified by assuming that diffusion is the predominant mechanism, thus motivating the characterisation of this transport property by most existing tests.

Current methods to access the concrete resistance to chloride attack may be classified as steady-state or non-steady-state, regarding the change in chloride-ion concentration in concrete, and as diffusion or migration tests, regarding the predominant driving transport mechanism [4]. Additionally, other tests based on indirect measurements of resistivity or conductivity can also be adopted [5-7]. In stationary tests, the diffusion coefficient is calculated by applying Fick's first law [8]. These tests do not consider the binding capacity 
of the cement paste and are affected by various factors, such as the specimen thickness, solution concentration, temperature and presence of other ions. Moreover, the time required to reach the steady-state can go from a few weeks to several months, depending on the depth of penetration and thickness of the specimens [2]. In non-stationary tests, the diffusion coefficient is calculated by considering Fick's second law [8]. In these tests, the chloride penetration can be evaluated by colorimetric methods, applying a solution of silver nitrate $\left(\mathrm{AgNO}_{3}\right)$, or more rigorously, by extracting samples at different depths and building chloride profiles [2,9]. In real exposure conditions, the penetration of chloride ions is affected by the chemical and physical interaction with the hydrated cement paste. Thus, the calculated diffusion coefficient is referred to as "apparent", given that it considers the total chloride concentration gradient as a driving force, even though the diffusion process only involves the flow of free chlorides in the pore solution. The major drawback of these tests is the fact that they require long exposure periods to obtain representative chloride profiles [3].

Among the existing non-stationary diffusion methods, the immersion test (IT) and the wetting and drying test (WDT) are those that better simulate the chloride ingress in submerged zone and tidal zone, respectively. In fact, the main advantage of these methods is their more accurate simulation of the chloride-ion penetration mechanism in natural environment, namely the diffusion mechanism in submerged conditions and the diffusion/absorption mechanisms in tidal regions (intermittent wetting and drying, leading to chloride penetration governed by absorption and diffusion mechanisms $[10,11]$ ), respectively. Besides the long duration, the change of the pore structure throughout the test, as a consequence of the hydration process, affects the chloride diffusion coefficient calculation, conflicting with the assumptions of Fick's second law [12]. In addition, the complex procedure for the determination of the chloride-ion concentration also introduces further difficulty regarding this less expeditious method $[1,13,14]$.

The long-lasting and laborious nature of common stationary or non-stationary diffusion tests shifted the focus towards accelerated migration methods, based on the induction of an electrical potential difference. In this case, the diffusion coefficient is estimated considering the similarity between diffusion and migration, by introducing the notion of ionic mobility $[7,10,15]$. Due to its simplicity and celerity, these methods are preferable in approximately characterising the chloride penetration resistance of concrete.

Whiting [16] proposed the rapid chloride permeability test (RCPT), which measures the amount of electrical current that passes through a specimen for a given time period. This test, adopted by AASHTO T 277 [17] and ASTM C 1202 [18], can provide an idea of the permeability of the concrete in just a few hours. However, various limitations have been pointed out in this test [6,19-21]. On the one hand, this test does not allow the direct assessment of chloride diffusion coefficients, establishing only a qualitative relationship between the chloride penetration resistance and the electrical current that passes through a concrete specimen [3,22]. On the other hand, for concrete with different types of cementitious materials, the pore composition is altered, affecting the passing charge and the microstructure differently. In fact, the RCPT only provides a measure of the concrete electrical conductivity that depends on the porous structure and composition of the pore solution, altered by mineral admixtures. In addition, the ion mobility is affected by the significant temperature increase during testing [2,22].

Alternatively, the rapid chloride migration test (RCMT), first proposed by Tang [23], and standardised through NT Build 492 [24], is a short-term non-steady-state method allowing the expeditious determination of the chloride migration coefficient $\left(D_{c l, R C M T}\right)$ of concrete [25]. This methodology is essentially based on the migration of chloride ions into previously lime-saturated concrete specimens by applying an external electrical voltage, which is adjusted according to the electrical current in the system $[9,26-28]$. The chloride ions are forced towards a downstream solution, and, after a short period, the chloride penetration depth is determined by a colorimetric indicator $\left(\mathrm{AgNO}_{3}\right)$ that changes colour at nearly $0.07 \mathrm{~mol} / \mathrm{dm}^{3}[24,26]$. Owing to its simplicity, short test duration (from 6 to $96 \mathrm{~h}$ ) 
and high repeatability, this method has been increasingly considered for the determination of chloride penetration resistance of concrete [26,28].

The penetration of chloride ions in the RCMT involves the combined mechanisms of diffusion and migration, where the flux follows the Nernst-Plank law [26,28,29]. Based on this, Equation (1) may be derived by simply assuming that the electrical field is constant across the specimen, that the chemical reactions with the hydrated paste are neglected, that there is no interaction with other ions and that the convection mechanisms are not significant $[2,5,22,30]$.

$$
\begin{gathered}
\frac{\partial c}{\partial t}=D_{c l, R C M T}\left(\frac{\partial^{2} c}{\partial x^{2}}-\frac{z F U}{R T L} \cdot \frac{\partial c}{\partial x}\right) \\
D_{c l, R C M T}=\frac{R T L}{z F E} \cdot \frac{x_{d}-\alpha \sqrt{x_{d}}}{t}, \text { where } E=\frac{U-2}{L} \text { and } \alpha=2 \cdot \sqrt{\frac{R T L}{z F E}} \cdot \operatorname{erf}^{-1}\left(1-\frac{2 c_{d}}{c_{0}}\right)
\end{gathered}
$$

From the analytical solution of Equation (1), Tang [23] derived Equation (2) that determines the non-steady migration coefficient $D_{c l, R C M T}$, where $z$ is the absolute value of ion valence for chloride $(z=1), F$ is the Faraday constant, $U$ stands for the absolute value of the applied voltage, $R$ is the gas constant, $T$ is the average value of the initial and final temperature in the anolyte solution, $L$ is the thickness of the specimen, $x_{d}$ is the average value of the penetration parameters, $t$ is the test duration, $\operatorname{erf}^{-1}$ is the inverse of error function, $c_{d}=0.07 \mathrm{~N}$ (chloride concentration at which the colour changes), and $c_{0}=2 \mathrm{~N}$ (chloride concentration of catholyte solution).

The wide acceptance of the RCMT led to the development of service life models based on this test, namely Duracrete [27], fib 34 [31] and LNEC E 465 [32]. Gjørv [33] suggested a classification for the chloride penetration resistance of concrete, according to different ranges of measured $D_{c l, R C M T}$ (Table 1).

Table 1. Chloride penetration resistance of concrete based on the RCMT (based on the results of Gjørv [33]).

\begin{tabular}{cc}
\hline Chloride Penetration Resistance of Concrete & $D_{c l, R C M T}\left(\times \mathbf{1 0}^{-\mathbf{1 2}} \mathbf{~}^{\mathbf{2}} / \mathbf{s}\right)$ \\
\hline Low & $>15$ \\
Moderate & $10-15$ \\
High & $5-10$ \\
Very high & $2.5-5$ \\
Extremely high & $<2.5$ \\
\hline
\end{tabular}

However, some limitations are attributed to the current RCMT. Regarding the theoretical background of the RCMT model, various authors have reported that real chloride concentration profiles from the RCMT greatly deviate from those theoretically predicted from the analytical solution of Equation (1), characterised by a sharp front $[3,26,28,29]$. Actually, the RCMT chloride profiles follow the same shape of long-term diffusion tests in saturated concrete [28,29]. According to Spiesz et al. [26], the equation to determine the $D_{c l, R C M T}$ fails in not considering the non-linearity of the chloride binding isotherm and non-equilibrium condition between free and bound chlorides. Regarding the free to bound chloride concentration, the equilibrium should not be attained during the short RCMT period [26]. This equilibrium is reported to be achieved only over 7-14 days [1,33]. For this reason, the diffusion coefficient determined in common long-term IT is not comparable to the RCMT. Therefore, $D_{c l, R C M T}$ tends to be overestimated, since it cannot explore the real chloride binding capacity of concrete [26].

Other simplification is related to the non-consideration of the interaction of other ionic species during migration. In fact, the pore solution is a multicomponent electrolyte with other ions participating in the process, such as $\mathrm{Na}^{+}, \mathrm{K}^{+}, \mathrm{Ca}^{2+}$ and $\mathrm{OH}^{-}$, with a given activity and diffusivity in different directions $[3,15,26,29]$. Spiesz et al. [26] showed that, 
during the RCMT, the resistivity of the sample increased, which was attributed to the densification of the pore system caused by chloride binding and the partial change of $\mathrm{OH}^{-}$ ions by free chloride ions in the pore solution. These factors make the modelling of the RCMT migration a complex process. Some more accurate models have been proposed, but their complexity is barely compatible with their simple practical application $[15,29]$.

The RCMT is also affected by the test conditions. The calculation of the $D_{c l, R C M T}$ requires the exact value of the electrical field across the concrete specimen. However, this value can be affected by the polarisation effect of the electrodes, causing a difference between the potential applied by the power source and the potential applied across the concrete specimen $[25,34]$. Moreover, the test conditions, namely the electrical current and temperature, are not constant during testing [28]. In addition, the hypothesis of constant electrical field across the specimen is only approximate [22]. However, Spiesz et al. [28] found that the $D_{c l, R C M T}$ is not significantly affected by the applied voltage, for the usual range considered in this test. According to Andrade [6], the RCMT resolution increases with the penetration depth. Spiesz et al. [26] also reported an increase of the sample mass during the RCMT related to further water uptake, which also affects the RCMT model.

As underlined in NTBuild 492 [24], the $D_{c l, R C M T}$ cannot be directly compared with the chloride diffusion coefficient obtained from diffusion tests, since it involves different mechanisms. However, to assess the validity of the RCMT, some authors have related this test with others, such as the long-term IT, which, as mentioned may be more representative of real exposure conditions $[1,8,10,11,26]$. A reasonable correlation has been found between the chloride diffusion from non-steady-state diffusion tests and the $D_{c l, R C M T}$, although the later tends to be higher $[1,8,10,11,26]$. This is attributed to the different chloride binding capacity and ionic interaction and activity in both tests [10,35]. According to Jen et al. [36] and Junior et al. [9], the RCMT may be less conservative than the IT from NT Build 443 [37], since the chloride binding capacity may be reduced. The Chlortest project [5], involving the collaboration of various European countries, found that the RCMT could be correlated with the IT from NT Build 443 [37]. The tests were carried out for different concrete compositions, with distinct water/binder ratios $(\mathrm{w} / \mathrm{b})(0.40,0.45)$ and types of binder (ordinary Portland cement (CEM I), silica fume (SF), fly ash (FA) and blast furnace slag (BFS)). In addition, a higher repeatability and reproducibility in the RCMT than in NTBuild 443 [37] was reported [5]. Frederiksen et al. [38] reported a high correlation between the RCMT and the IT (35 days in $165 \mathrm{~g} / \mathrm{dm}^{3} \mathrm{NaCl}$ ), for 28 days-cured concrete with $\mathrm{w} / \mathrm{b}$ ranging from 0.30 to 0.70. Similarly, Tang et al. [35] found a high correlation between the RCMT and the IT results for concrete with $100 \%$ CEM I, with 8 weight percentage $(\mathrm{wt} \%)$ replacement of $\mathrm{SF}$, or with $70 \mathrm{wt} \%$ replacement of BFS. Bogas et al. [10] found a poor correlation between the $D_{c l, R C M T}$ and the diffusion coefficients of concretes with FA immersed in a $\mathrm{NaCl}$ solution for 28 and 225 days. This was related to the early age testing of RCMT that did not allow the sufficient reaction of FA. A reasonable relationship between the RCMT and NTBuild 443 [37] was found by Junior et al. [9], considering concrete with $12 \%$ and $27 \%$ FA, tested at 90 days, to allow a more efficient contribution of this addition.

The influence of the type of aggregate in the relation between the RCMT and other tests has been barely studied. Noteworthy is the study of Bogas et al. [10], involving a narrow set of lightweight aggregate concrete (LWAC) and normal weight concrete (NWC) compositions. The authors reported the same trend for the diffusion coefficients in the RCMT and the long-term IT, up to 225 days. However, the participation of lightweight aggregates (LWA) is known to depend on the exposure conditions and concrete composition, which may affect the validity of the RCMT $[10,39,40]$. Further research is needed in this domain.

Despite involving different chloride penetration mechanisms, the RCMT is also adopted for service life models involving other exposure conditions [27,41]. However, the capacity of the RCMT in assessing the chloride penetration resistance of concrete under different environments, such as in wetting and drying conditions, still needs to be explored, especially, taking into account different concrete compositions. Therefore, although few 
studies have been conducted regarding the comparison of different chloride penetration tests in conventional concretes, a comparison with a wider and diverse set of concrete compositions is needed to further evaluate the relationship between the RCMT and the long-term tests, simulating real chloride environments, namely the IT and the WDT. In this study, the sensitivity of the RCMT to assess the chloride penetration resistance of most common NWC and LWAC used in the construction industry is analysed, by comparing the results with the performance of the same concretes under long-term chloride penetration tests. To this end, RCMT, IT and WDT were carried out for a wide range of concretes with different $w / b$, types and amounts of binder and types of aggregate.

\section{Experimental Programme}

\subsection{Materials}

The NWC were produced with three types of coarse crushed limestone normal weight aggregates (NWA) of different grain sizes (fine gravel, coarse gravels 1 and 2) and two types of natural siliceous sand. In LWAC, the coarse NWA were replaced by LWA with distinct porosities, namely one expanded clay aggregate from Portugal (Leca) and one expanded slate aggregate from the USA (Stalite). The main properties of these aggregates are listed in Table 2.

Table 2. Aggregate properties.

\begin{tabular}{|c|c|c|c|c|c|c|c|}
\hline \multirow[t]{2}{*}{ Property } & \multicolumn{5}{|c|}{ Normal Weight Aggregates } & \multicolumn{2}{|c|}{$\begin{array}{l}\text { Lightweight } \\
\text { Aggregates }\end{array}$} \\
\hline & $\begin{array}{l}\text { Fine } \\
\text { Gravel }\end{array}$ & $\begin{array}{c}\text { Coarse } \\
\text { Gravel } 1\end{array}$ & $\begin{array}{c}\text { Coarse } \\
\text { Gravel } 2\end{array}$ & $\begin{array}{l}\text { Fine } \\
\text { Sand }\end{array}$ & $\begin{array}{c}\text { Coarse } \\
\text { Sand }\end{array}$ & Leca & Stalite \\
\hline Oven-dried particle density $\left(\mathrm{kg} / \mathrm{m}^{3}\right)$ & 2646 & 2683 & 2618 & 2605 & 2617 & 969 & 1483 \\
\hline Loose bulk density $\left(\mathrm{kg} / \mathrm{m}^{3}\right)$ & 1309 & 1346 & 1325 & 1569 & 1708 & 632 & 760 \\
\hline Absorption at $24 \mathrm{~h}(\%)$ & 0.7 & 0.4 & 1.1 & 0.2 & 0.3 & 16.3 & 3.6 \\
\hline Granulometric fraction (d/D) & $0 / 8$ & $4 / 11.2$ & $11.2 / 20$ & $0 / 1$ & $0 / 4$ & $4 / 10$ & $8 / 16$ \\
\hline Open porosity (\%) & - & - & - & - & - & 40.7 & 14.9 \\
\hline
\end{tabular}

Cement type I $42.5 \mathrm{R}$ (CEM I), lime filler (LF) with $38.6 \%$ residue on the $45 \mu \mathrm{m}$ sieve, class F FA with $13.8 \%$ residue on the $45 \mu \mathrm{m}$ sieve and an activity index of $75 \%$ at 28 days and $\mathrm{SF}$ with $94.3 \%$ of $\mathrm{SiO}_{2}$ and an activity index of $80 \%$ at 28 days, were considered for the binder phase (Table 3). A polycarboxylate based superplasticizer (SP) was also used for concretes with low $\mathrm{w} / \mathrm{b}$.

Table 3. Cement and mineral admixture properties.

\begin{tabular}{ccccc}
\hline Property & $\begin{array}{c}\text { Cement I 42.5R } \\
\text { (CEM I) }\end{array}$ & Silica Fume (SF) & Fly Ash (FA) & Lime Filler (LF) \\
\hline Density $\left(\mathrm{g} / \mathrm{cm}^{3}\right)$ & 3.08 & 2.21 & 2.32 & 2.69 \\
Specific surface $\left(\mathrm{cm}^{2} / \mathrm{g}\right)$ & 4388 & 2730 & 3320 & 7430 \\
Loss on ignition $(\%)$ & 3.64 & 2.68 & 5.80 & 40.68 \\
$\mathrm{SiO}_{2}+\mathrm{Al}_{2} \mathrm{O}_{3}+\mathrm{Fe}_{2} \mathrm{O}_{3}(\%)$ & $18.49+4.95+3.61$ & $94.31+\mathrm{ND}+0.03$ & $50.16+25.62+7.14$ & $5.05+1.34+0.82$ \\
$\mathrm{CaO}+\mathrm{MgO}(\%)$ & $63.11+1.62$ & $4.29+0.91$ & $2.13+0.41$ & $50.89+0.57$ \\
\hline
\end{tabular}

\subsection{Mixture Composition and Concrete Production}

The mixture compositions are indicated in Table 4 . The concretes were produced with $\mathrm{w} / \mathrm{b}$ of $0.35-0.55$ and distinct types and amounts of binder, in order to cover a wide range of common concrete used in the construction industry. 
Table 4. Concrete mixture compositions for NWC and SLWAC produced with different types of binder and of aggregate.

\begin{tabular}{|c|c|c|c|c|c|c|c|c|}
\hline \multirow{2}{*}{$\begin{array}{c}\text { Type of } \\
\text { Aggregate }\end{array}$} & \multirow{2}{*}{ Type of Binder } & \multirow{2}{*}{$\begin{array}{c}\text { Mineral } \\
\text { Addition (wt } \% \\
\text { of Binder) }\end{array}$} & \multirow{2}{*}{$w / b$} & \multirow{2}{*}{$\begin{array}{l}M_{\text {binder }} \\
\left(\mathrm{kg} / \mathrm{m}^{3}\right)\end{array}$} & \multirow{2}{*}{$\begin{array}{c}\mathrm{V}_{\text {coarse aggregate }} \\
\left(\mathrm{L} / \mathrm{m}^{3}\right)\end{array}$} & \multicolumn{2}{|c|}{$\mathrm{V}_{\text {sand }}\left(\mathrm{L} / \mathrm{m}^{3}\right)$} & \multirow{2}{*}{$\begin{array}{c}\mathrm{V}_{\text {water,ef }} \\
\left(\mathrm{L} / \mathrm{m}^{3}\right)\end{array}$} \\
\hline & & & & & & $\begin{array}{l}\text { Fine } \\
\text { Sand }\end{array}$ & $\begin{array}{c}\text { Coarse } \\
\text { Sand }\end{array}$ & \\
\hline \multirow{18}{*}{ NWA } & CEM I & - & \multirow{6}{*}{0.35} & \multirow{6}{*}{450} & 436 & 80 & 154 & \multirow{6}{*}{157.5} \\
\hline & CEM II/A-D & $6 \% \mathrm{SF}$ & & & 433 & 80 & 153 & \\
\hline & CEM II/A-V & $15 \%$ FA & & & 431 & 80 & 152 & \\
\hline & CEM II/B-V & $30 \%$ FA & & & 419 & 72 & 164 & \\
\hline & CEM II/A-L & $15 \% \mathrm{LF}$ & & & 427 & 87 & 153 & \\
\hline & CEM II/B-L & $30 \% \mathrm{LF}$ & & & 424 & 80 & 159 & \\
\hline & CEM I & - & \multirow{6}{*}{0.45} & \multirow{6}{*}{400} & 412 & 106 & 146 & \multirow{6}{*}{180} \\
\hline & CEM II/A-D & $6 \% \mathrm{SF}$ & & & 411 & 106 & 146 & \\
\hline & CEM II/A-V & $15 \%$ FA & & & 408 & 105 & 145 & \\
\hline & CEM II/B-V & $30 \%$ FA & & & 406 & 104 & 144 & \\
\hline & CEM II/A-L & $15 \% \mathrm{LF}$ & & & 411 & 104 & 146 & \\
\hline & CEM II/B-L & $30 \% \mathrm{LF}$ & & & 409 & 106 & 145 & \\
\hline & CEM I & - & \multirow{6}{*}{0.55} & \multirow{6}{*}{350} & 401 & 114 & 154 & \multirow{6}{*}{192.5} \\
\hline & CEM II/A-D & $6 \% \mathrm{SF}$ & & & 400 & 113 & 153 & \\
\hline & CEM II/A-V & $15 \%$ FA & & & 399 & 106 & 159 & \\
\hline & CEM II/B-V & $30 \%$ FA & & & 395 & 105 & 158 & \\
\hline & CEM II/ A-L & $15 \% \mathrm{LF}$ & & & 400 & 107 & 160 & \\
\hline & CEM II/B-L & $30 \% \mathrm{LF}$ & & & 399 & 106 & 159 & \\
\hline \multirow{3}{*}{ Leca } & \multirow{3}{*}{ CEM I } & \multirow{3}{*}{-} & 0.35 & 450 & 355 & 201 & 114 & 157.5 \\
\hline & & & 0.45 & 400 & 353 & 186 & 126 & 180 \\
\hline & & & 0.55 & 350 & 355 & 181 & 134 & 192.5 \\
\hline \multirow{3}{*}{ Stalite } & \multirow{3}{*}{ CEM I } & \multirow{3}{*}{-} & 0.35 & 450 & 355 & 214 & 100 & 157.5 \\
\hline & & & 0.45 & 400 & 353 & 213 & 100 & 180 \\
\hline & & & 0.55 & 350 & 355 & 201 & 114 & 192.5 \\
\hline
\end{tabular}

The type of binder involves the reference cement Type I (CEM I), as well as representative Portland-composite cements Type II/A and II/B, according to EN 197-1 [42]. LWAC of equal composition, but with only CEM I was produced to assess the influence of the type of aggregate. The volume of water $\left(\mathrm{V}_{\text {water,eff }}\right)$ refers to the effective water used. The $\mathrm{SP}$ was used in concrete with $\mathrm{w} / \mathrm{b}$ of 0.35 and 0.45 . The concrete mixtures were designed for a $12 \mathrm{~cm}$ slump.

The concretes were produced in a vertical shaft mixer with bottom discharge. First, the aggregates were placed in the mixer with about $50 \%$ of the mixing water. After mixing for $2 \mathrm{~min}$, the mixture was left to rest for $1 \mathrm{~min}$ before adding the binder and the rest of the water. When used, the SP was slowly added with $10 \%$ of water, after another minute. The total mixing time was $7 \mathrm{~min}$. For LWAC, the LWA were previously soaked for $24 \mathrm{~h}$ and surface dried to ensure a better control of the workability and the effective water content of concrete.

\subsection{Specimen Preparation and Test Methods}

The following specimens were produced for each mixture: two $100 \mathrm{~mm}$ cubic specimens to determine the dry density of concrete, according to EN 12390-7 [43]; three $150 \mathrm{~mm}$ cubic specimens for compressive strength at 28 days, according to EN 12390-3 [44]; three sawn $\phi 100 \times 50 \mathrm{~mm}$ specimens, for the RCMT, according to NT Build 492 [24]; one $150 \mathrm{~mm}$ cube for the IT, according to LNEC E 390 [45]; one $150 \mathrm{~mm}$ cube for the non-standard WDT.

\subsubsection{Curing Procedure}

After demoulding at $24 \mathrm{~h}$, two curing procedures were adopted, depending on each test. For the density and compressive strength tests, the specimens were kept in water until testing at 28 days. For the RCMT, the specimens were kept in water for 7 days, cut to 
specifications and placed in a chamber at $20{ }^{\circ} \mathrm{C}$ and $50 \%$ relative humidity. In the IT and the WDT, the specimens were kept in water until 21 days. After 21 days, all surfaces of the cubic specimens adopted in the IT and the WDT were protected with a waterproofing paint to ensure uniaxial chloride penetration, except the one perpendicular to the casting direction. Then, the cubes were immersed in a calcium hydroxide $\left.(\mathrm{CaOH})_{2}\right)$ saturated water solution until constant mass, before testing.

\subsubsection{Rapid Chloride Migration Test}

The chloride penetration resistance was assessed by means of the non-steady-state RCMT specified in NT Build 492 [24]. The test consisted of applying an external electrical potential for a certain amount of time, forcing the chloride ions in the sodium chloride $(\mathrm{NaCl})$ solution to migrate into the specimen. The time of the test depended on the applied voltage. Then, the specimen was split into two halves and sprayed with an $\mathrm{AgNO}_{3}$ solution. The chloride penetration depth corresponded to the visible limit of the white silver chloride precipitation. The non-steady-state chloride migration coefficient, $D_{c l, R C M T}$, was calculated according to Equation (2). One day before testing, the specimens were vacuum saturated with a $\mathrm{Ca}(\mathrm{OH})_{2}$ solution. The tests were carried out at 28 days.

\subsubsection{Immersion Test}

The IT was based on LNEC specification E 390 [45]. The specimens were immersed in a tank (Figure 1) filled with a solution composed of $\mathrm{Ca}(\mathrm{OH})_{2}$ saturated water and $15 \%$ $\mathrm{NaCl}$, which was renewed every month.

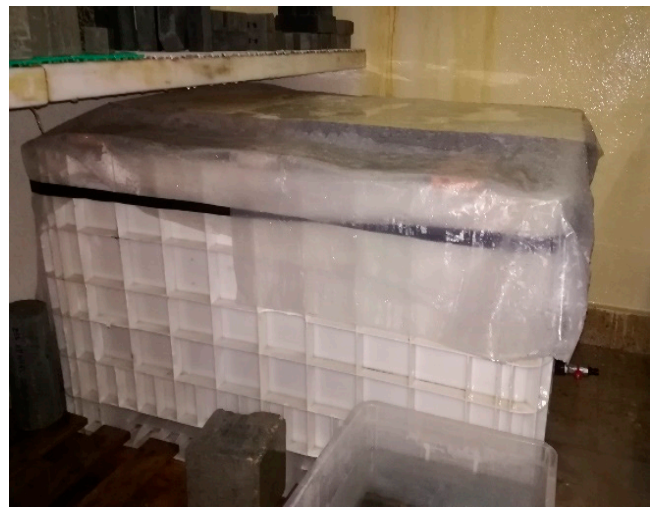

(a)

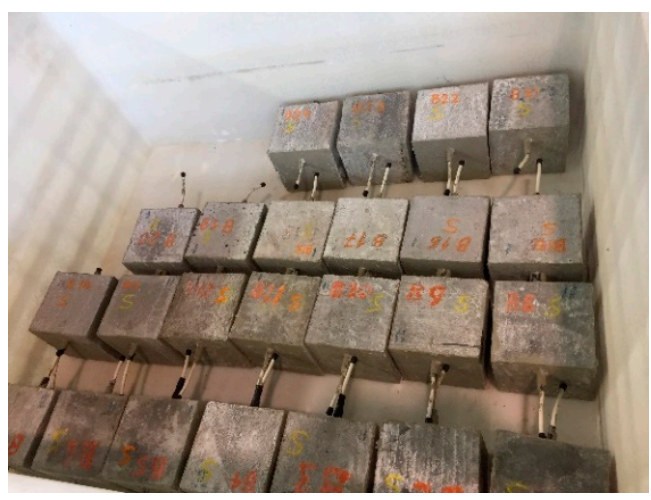

(b)

Figure 1. IT tank (a) and test specimens (b).

After 3 months, 6 samples were collected from each specimen at different depths $(5,10$, $15,20,25$ and $30 \mathrm{~mm}$ ), obtained from two $25 \mathrm{~mm}$ drill holes, following the recommendation of Kropp [46].

\subsubsection{Wetting-Drying Test}

The WDT is not a standardised test, although it has been performed by various authors [47-49], in order to simulate tidal conditions (Figure 2). The test consisted of 3-days wetting and 4-days drying cycles at laboratory temperature, as also adopted by Otieno et al. [45,47]. The same saline solution used in the IT was adopted for this test and was renewed every month. Similarly to IT, after 3 months, 6 samples were collected from two $25 \mathrm{~mm}$ drill holes in each specimen, at different depths (5,10, 15, 20, 25 and $30 \mathrm{~mm})$. 


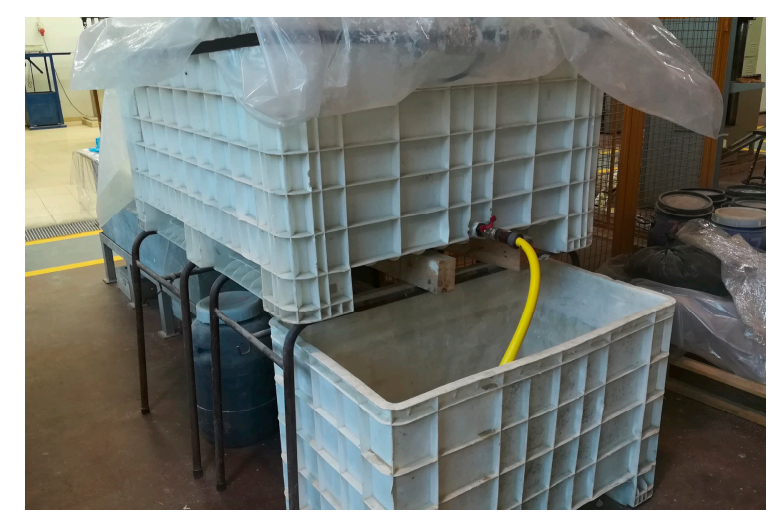

Figure 2. WDT tank with the solution containment tank.

\subsubsection{Chloride Profiles and Parameter Determination}

Before the IT and the WDT, reference samples were collected from the cubic specimens to determine the initial chloride content $\left(C_{i}\right)$. This parameter ranged from 0.04 to $0.16 \mathrm{wt} \%$ of binder, which was lower than the maximum $0.2 \mathrm{wt} \%$ of binder, recommended in EN 206 [50], for reinforced concrete under XS classes.

After the sample collection from the IT and WDT specimens, the total chloride concentration was determined through potentiometric titration, by resorting to a $\mathrm{pH} / \mathrm{ISE}$ meter and an electrode, similarly to the method suggested in ASHTOO T260 [51], as described in Real and Bogas [52]. Knowing the measured chloride content at different depths, a chloride profile was built for each type of concrete. Using non-linear regression (NLR) with the assistance of the software $R$ Studio (Version 1.1.442), the apparent diffusion coefficient, $D_{c l}$ $\left(\mathrm{m}^{2} / \mathrm{s}\right)$, and the surface chloride content, $C_{s}$ ( $\mathrm{wt} \%$ of binder), were obtained by curve fitting to Equation (3), where $C_{i}$ is the initial chloride content (wt\% of binder), $x_{c l}$ is the depth of chloride penetration (m) at exposure time $t(\mathrm{~s})$, and erf is the error function, originated from solving Fick's second law of diffusion. In this case, since the diffusion coefficient is time-dependent, the $D_{c l}$ actually represents an average diffusion coefficient during the exposure time.

$$
C(x, t)=C_{i}+\left(C_{s}-C_{i}\right) \times\left[1-\operatorname{erf}\left(\frac{x_{c l}}{2 \times \sqrt{D_{c l} \times t}}\right)\right]
$$

In addition, the penetration parameter, $K_{c r}$, was determined through Equation (4), according to LNEC E-390 [45]. This parameter is useful for comparison purposes and represents the one-year penetration depth of a reference chloride content, $C_{r}$, if $D_{c l}$ is constant. A reference $C_{r}$ of $0.5 \mathrm{wt} \%$ of binder was considered [53].

$$
K_{c r}=2 \sqrt{D_{c l}} * e r f^{-1}\left(\frac{C_{s}-C_{r}}{C_{s}-C_{i}}\right)
$$

\section{Results and Discussion}

Table 5 presents the results of the 28 days chloride migration coefficient $\left(D_{c l, R C M T}\right)$ from the RCMT, and the 90 days chloride diffusion coefficient $\left(D_{c l, I T}\right.$ and $\left.D_{c l, W D T}\right)$, surface chloride content $\left(C_{s, I T}\right.$ and $\left.C_{s, W D T}\right)$ and penetration parameter $\left(K_{c r, I T}\right.$ and $\left.K_{c r, W D T}\right)$ from the IT and WDT. The coefficient of variation (CV) of the RCMT was lower than $9 \%$, which is within the maximum of $15 \%$ indicated in literature [5]. 
Table 5. Chloride ingress results from the three test methods.

\begin{tabular}{|c|c|c|c|c|c|c|c|c|c|c|c|c|c|}
\hline \multirow[b]{2}{*}{$\begin{array}{c}\text { Type of } \\
\text { Aggregate }\end{array}$} & \multirow[b]{2}{*}{$\begin{array}{l}\text { Type of } \\
\text { Binder }\end{array}$} & \multirow[b]{2}{*}{$w / b$} & \multirow{2}{*}{$\begin{array}{l}\text { Compressive } \\
\text { Strength at } \\
28 \text { Days } \\
\text { (MPa) }\end{array}$} & \multirow[b]{2}{*}{$\begin{array}{c}\text { Dry } \\
\text { Density } \\
\left(\mathrm{kg} / \mathrm{m}^{3}\right)\end{array}$} & \multicolumn{3}{|c|}{ Rapid Chloride Migration Test } & \multicolumn{3}{|c|}{ Immersion Test } & \multicolumn{3}{|c|}{ Wetting-Drying Test } \\
\hline & & & & & $\underset{\left(\times 10^{-12} \mathrm{~m}^{2} / \mathrm{s}\right)}{\mathrm{D}_{\mathrm{cl}, \mathrm{RCMT}}}$ & CV (\%) & $\begin{array}{l}\text { Gjørv [33] } \\
\text { Classification }\end{array}$ & $\underset{\left(\times 10^{-12} \mathrm{~m}^{2} / \mathrm{s}\right)}{\mathrm{D}_{\mathrm{cl}, \mathrm{IT}}}$ & $\begin{array}{l}\mathrm{C}_{\mathrm{S}, \mathrm{IT}}(\mathrm{wt} \% \\
\text { Binder) }\end{array}$ & $\underset{\left(\mathrm{mm} / \mathbf{y}^{0.5}\right)}{\mathrm{K}_{\mathrm{cr}, \mathrm{IT}}}$ & $\begin{array}{c}\mathrm{D}_{\mathrm{cl}, \mathrm{WDT}} \\
\left(\times 10^{-12} \mathrm{~m}^{2} / \mathrm{s}\right)\end{array}$ & $\begin{array}{c}\mathrm{C}_{\mathrm{s}, \mathrm{WDT}} \\
(\mathrm{wt} \% \\
\text { Binder) }\end{array}$ & $\begin{array}{c}\mathrm{K}_{\mathrm{cr}, \mathrm{WDT}} \\
\left(\mathrm{mm} / \mathrm{y}^{0.5}\right)\end{array}$ \\
\hline \multirow{14}{*}{ NWA } & \multirow{3}{*}{ CEM I } & 0.35 & 77.0 & 2330 & 10.0 & 6 & Moderate & 2.3 & 2.3 & 14.9 & 2.9 & 2.3 & 16.7 \\
\hline & & 0.45 & 58.1 & 2270 & 13.5 & 0 & Moderate & 4.2 & 2.4 & 20.6 & 5.3 & 2.9 & 25.0 \\
\hline & & 0.55 & 47.7 & 2230 & 17.0 & 3 & Low & 5.9 & 3.4 & 27.9 & 6.9 & 3.7 & 31.2 \\
\hline & \multirow{3}{*}{$\begin{array}{l}\text { CEM } \\
\text { II/A-D }\end{array}$} & 0.35 & 78.0 & 2290 & 5.9 & 0 & Very High & 1.3 & 1.6 & 9.4 & 1.2 & 2.5 & 11.2 \\
\hline & & 0.45 & 51.5 & 2220 & 9.0 & 2 & High & 2.7 & 3.3 & 18.6 & 2.5 & 2.7 & 16.5 \\
\hline & & 0.55 & 44.5 & 2200 & 14.2 & 4 & Moderate & 5.2 & 3.8 & 27.4 & 8.6 & 5.2 & 38.6 \\
\hline & \multirow{3}{*}{$\begin{array}{l}\text { CEM } \\
\text { II/A-V }\end{array}$} & 0.35 & 63.2 & 2300 & 9.7 & 3 & High & 1.3 & 3.1 & 12.6 & 1.4 & 3.4 & 13.6 \\
\hline & & 0.45 & 49.6 & 2250 & 16.7 & 9 & Low & 2.8 & 4.0 & 20.5 & 2.0 & 5.3 & 18.9 \\
\hline & & 0.55 & 38.6 & 2230 & 23.3 & 3 & Low & 5.8 & 4.4 & 30.2 & 3.5 & 4.0 & 22.7 \\
\hline & \multirow{3}{*}{$\begin{array}{l}\text { CEM } \\
\text { II/B-V }\end{array}$} & 0.35 & 56.0 & 2270 & 9.7 & 6 & High & 1.2 & 4.3 & 13.5 & 0.9 & 7.6 & 14.1 \\
\hline & & 0.45 & 44.6 & 2250 & 18.5 & 3 & Low & 1.3 & 4.4 & 14.1 & 1.5 & 5.3 & 16.3 \\
\hline & & 0.55 & 30.7 & 2200 & 25.2 & 5 & Low & 2.2 & 5.1 & 19.4 & 1.6 & 5.6 & 17.2 \\
\hline & $\begin{array}{l}\text { CEM } \\
\text { II/A-L }\end{array}$ & 0.35 & 62.0 & 2310 & 12.0 & 4 & Moderate & 3.7 & 2.3 & 18.6 & 2.6 & 1.6 & 12.8 \\
\hline & $\begin{array}{c}\text { CEM } \\
\text { II/B-L } \\
\end{array}$ & 0.35 & 53.2 & 2280 & 15.1 & 1 & Low & 15.4 & 1.7 & 33.3 & 6.7 & 2.8 & 27.7 \\
\hline \multirow{3}{*}{ Stalite } & \multirow{3}{*}{ CEM I } & 0.35 & 66.1 & 1920 & 10.6 & 2 & Moderate & 2.6 & 2.7 & 16.9 & 1.8 & 3.7 & 16.1 \\
\hline & & 0.45 & 51.1 & 1820 & 11.8 & 3 & Moderate & 4.1 & 2.2 & 19.6 & 4.4 & 3.1 & 23.2 \\
\hline & & 0.55 & 41.1 & 1800 & 16.3 & 7 & Low & 4.9 & 3.6 & 25.9 & 6.1 & 4.1 & 30.3 \\
\hline \multirow{3}{*}{ Leca } & \multirow{3}{*}{ CEM I } & 0.35 & 35.9 & 1660 & 12.0 & 3 & Moderate & 3.8 & 2.4 & 19.7 & 1.9 & 1.7 & 11.7 \\
\hline & & 0.45 & 30.3 & 1620 & 13.6 & 4 & Moderate & 5.9 & 4.6 & 31.0 & 6.6 & 3.1 & 28.7 \\
\hline & & 0.55 & 26.1 & 1600 & 19.5 & 4 & Low & 10.1 & 5.8 & 43.2 & 10.4 & 6.1 & 44.6 \\
\hline
\end{tabular}


The 28 days dry density and compressive strength are also presented in Table 5. Depending on the type of binder and $\mathrm{w} / \mathrm{b}$, the compressive strength of NWC varied between 30.7 and $78.0 \mathrm{MPa}$, within the strength classes C20/25-C60/75, according to EN 206 [50]. The dry density and compressive strength of LWAC varied between 1600 and $1920 \mathrm{~kg} / \mathrm{m}^{3}$ and 26.1 and $66.1 \mathrm{MPa}$, ranging from density classes D1.6-2.0 and strength classes LC20/22 to LC60/66, according to EN 206 [50], respectively. Moreover, the $D_{c l, R C M T}$ varied between $5.9 \times 10^{-12}$ and $25.2 \times 10^{-12} \mathrm{~m}^{2} / \mathrm{s}$, covering concrete of high to low quality, according to the classification of Gjørv [33] (Table 1). Thus, it was possible to cover a wide range of common structural concretes, broadening the scope and validation of this study.

\subsection{Influence of the Type of Binder on the Chloride Penetration Resistance}

Figure 3 presents the variation of $D_{c l, R C M T}$ with the $\mathrm{w} / \mathrm{b}$, according to the results of the present study and of other authors $[10,31,54,55]$. The $D_{c l, R C M T}$ was essentially dependent on the concrete microstructure, thus having increased with the $\mathrm{w} / \mathrm{b}$, regardless of the type of binder and aggregate (Figures 3 and 4, Table 5), similarly to the literature $[10,31,54,55]$. Furthermore, the results obtained in this study as a function of the $\mathrm{w} / \mathrm{b}$ for CEM I were in the same range as those reported by other authors [10,31,54,55] (Figure 3).

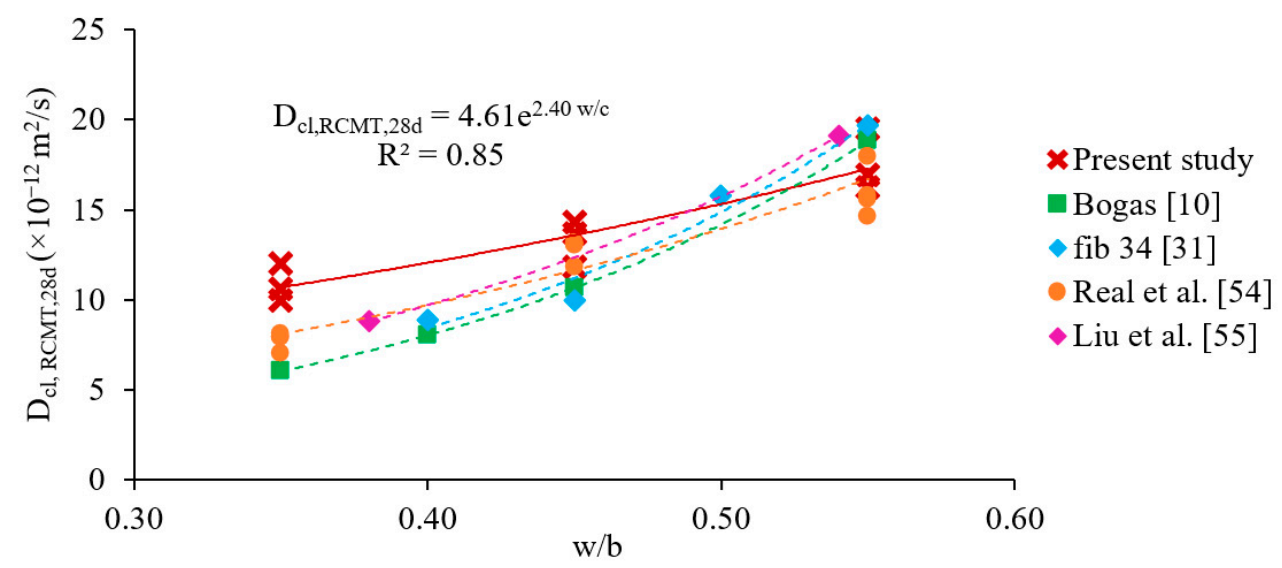

Figure 3. Chloride migration coefficient, $D_{c l, R C M T}$, versus $\mathrm{w} / \mathrm{b}$, considering this study and other authors $[10,31,54,55]$.

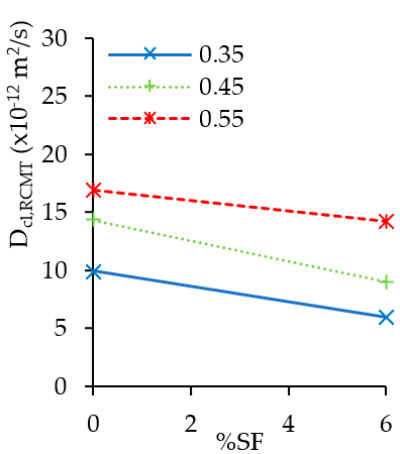

(a)

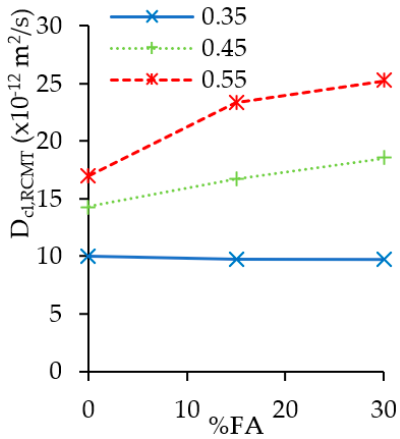

(b)

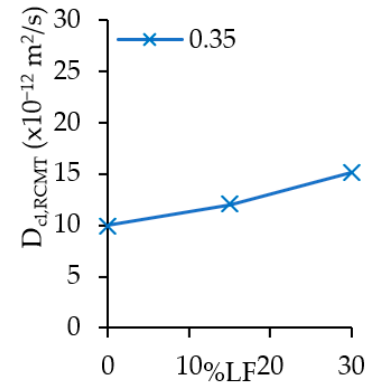

(c)

Figure 4. Chloride migration coefficient, $D_{c l, R C M T}$, as a function of percentage incorporation of $\mathrm{SF}(\mathbf{a})$, FA (b) and LF (c).

Figure 4 presents the variation of $D_{c l, R C M T}$ with the type and replacement percentage of binder in NWC with different $w / b$. As reported in literature, for the same $w / b$, the $D_{c l, R C M T}$ was affected by the type and amount of mineral admixture $[54,56,57]$.

The incorporation of $6 \% \mathrm{SF}$ led to a significant reduction of $D_{c l, R C M T}$, of $41 \%, 33.3 \%$ and $16.5 \%$, for $\mathrm{w} / \mathrm{b}$ of $0.35,0.45$ and 0.55 , respectively. According to the classification of 
Gjørv [33], the chloride penetration resistance of concrete increased one level with the addition of $6 \%$ SF (Table 5). This significant improvement is not only attributed to a possible refinement of the porous structure, but also to the alteration of the pore solution composition $[54,58]$, which may affect the interaction of ionic species and chloride migration. This is in line with the insignificant contribution of the SF found in the compressive strength (Table 5). One reason for the unexpectedly low contribution of SF to the microstructure refinement and strength improvement should be related to the poor dispersion of this high-fineness addition, which was supplied in an agglomerated state (Table 3).

As indicated, the efficiency of this pozzolanic addition was higher in low $\mathrm{w} / \mathrm{b}$ concrete. Contrarily, Khayat et al. [59] found that the effect of SF on the pore refinement tended to decrease with the reduction of $w / b$. This opposite trend may be related to the use of SP in low $\mathrm{w} / \mathrm{b}$ concrete, helping the better dispersion of mineral additions. Another reason may be related to a greater influence of these admixtures on the pore solution and ionic interaction of low $\mathrm{w} / \mathrm{b}$ concrete.

The influence of the incorporation of FA on the $D_{c l, R C M T}$ depended on the $\mathrm{w} / \mathrm{b}$. Once more, the FA was more effective in low $\mathrm{w} / \mathrm{b}$ concrete, showing similar $D_{c l, R C M T}$ to those of reference concrete with only CEM I, regardless of the replacement percentage. The $D_{c l, R C M T}$ increased up to $27 \%$ and $33 \%$ with the incorporation of $\mathrm{FA}$, for $\mathrm{w} / \mathrm{b}$ of 0.45 and 0.55 , respectively. This is related to the reduced wet curing period (7 days), early testing age (28 days) and low activity index of FA (Section 2.1) [54,60-63]. Thomas and Bamforth [57] also documented a lower influence of FA at early age. A greater contribution of this slow-reactive addition is thus expected to occur at later ages [64,65]. A correspondent reduction of the compressive strength was also found with the incorporation of FA, having been $27 \%, 23 \%$ and $36 \%$ lower than those of reference concrete with $\mathrm{w} / \mathrm{b}$ of $0.35,0.45$ and 0.55 , respectively. This confirms the lower volume of hydration products formed in FA concrete at 28 days. The results also suggest that the incorporation of FA led to a less dense microstructure in low $\mathrm{w} / \mathrm{b}$ concrete, supporting the idea that other factors contribute to the reduction of $D_{c l, R C M T}$ in these concretes.

A significant reduction of the $D_{c l, R C M T}$ over 28 days is documented by Liu et al. [62] and Real et al. [54]. Junior et al. [9] reported the reduction of porosity and pore refinement in concrete with $27 \%$ FA water cured for 90 days, suggesting a greater chloride binding capacity of concrete with FA compared to concrete with CEM I [20]. In fact, the high alumina content of FA may contribute to the chemical binding of chloride ions $[2-5,9,56]$.

Moreover, the extra C-S-H content helps to reduce the concrete permeability and increase the chloride binding by physical adsorption [26]. However, a low chloride binding capacity is expected in the short-term RCMT [23]. According to Chlortest [5], the binding properties in the RCMT should be low, due to its short duration and high voltage. Nevertheless, Spiesz et al. [26] showed that, in the RCMT, the ionic transport rate and test duration are not fast enough to avoid the chloride binding, confirming its presence. From MIP and SEM analysis, Junior et al. [9] also reported evidence of the formation of Friedel's salt, demonstrating the occurrence of chloride binding during the RCMT. The authors also found that the amount of Friedel's salt increased with the FA content. However, according to Spiesz et al. [26], the binding is not complete, because it is not an instantaneous process. In this case, less chloride ions are bound, and thus more free chloride ions penetrate further and, consequently, a larger $D_{c l, R C M T}$ tends to be conservatively obtained. The movement of other ions, such as $\mathrm{OH}^{-}$(different content in FA concrete) also alters the $\mathrm{pH}$ of pore solution, which is known to affect the chloride binding properties $[1,20,23,26]$, besides the ionic interactions.

The substitution of CEM I with LF diluted the amount of hydration products, contributing to a respective reduction on both compressive strength and chloride penetration resistance (Figure 4). For the same amount of binder, the reduction was higher in concrete with LF than with FA. Due to its high specific surface (Table 3), LF would be expected to contribute to the microstructure refinement by filler and nucleation effects $[53,66]$. However, 
these phenomena did not compensate the reduction of CEM I content. The incorporation of LF led to a reduction of the classification level of chloride penetration resistance (Table 5).

The chloride diffusion coefficients of the IT, $D_{c l, I T}$, and the WDT, $D_{c l, W D T}$, after 3 months are presented in Figure 5 In general, the $D_{c l, I T}$ and the $D_{c l, W D T}$ were up to about 4 times lower than that of $D_{c l, R C M T}$. On one hand, as reported in various studies, the $D_{c l}$ tends to reduce over time $[10,56]$. Therefore, the obtained $D_{c l, I T}$ and $D_{c l, W D T}$ are apparent values that correspond to the average time-dependent variation of this parameter over time, which is lower in the IT and the WDT, up to 120 days age, than in the almost instantaneous RCMT performed at 28 days. On the other hand, as mentioned, the RCMT leads to more conservative values of $D_{c l}$, due to the simplifications discussed in Section 1 and because chloride binding is less effective during this test. In general, for a given $\mathrm{w} / \mathrm{b}$, comparable $D_{c l}$ were obtained in the IT and the WDT for concrete with $\mathrm{w} / \mathrm{b}$ of 0.35 and 0.45 . In these cases, a clear variation of the $D_{c l}$ with the type of test was not observed. As presented in Figure 6, the chloride profiles displayed the same shape in the IT and the WDT, with the predominant development of the diffusion mechanism and absence of a clear convection region. In fact, the saturation level of low $\mathrm{w} / \mathrm{b}$ concretes in the WDT should be high, given the imposed short drying periods during this test (Section 2.3.4). However, for high $\mathrm{w} / \mathrm{b}$ concrete, some cases revealed a tendency for higher $D_{c l}$ in the WDT than in the IT (Table 5). This should be related to the easier drying in these high $\mathrm{w} / \mathrm{b}$ concretes, where convection was more relevant.

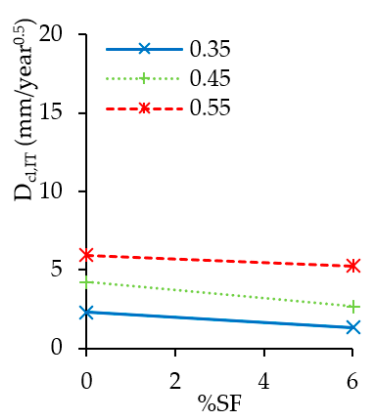

(a)

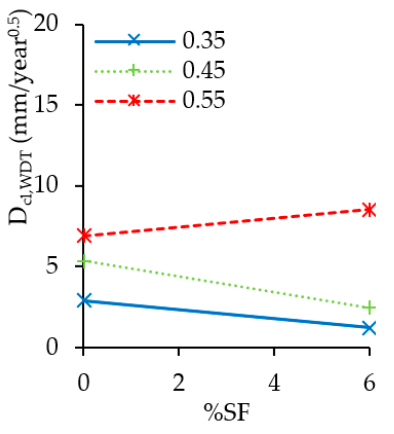

(d)

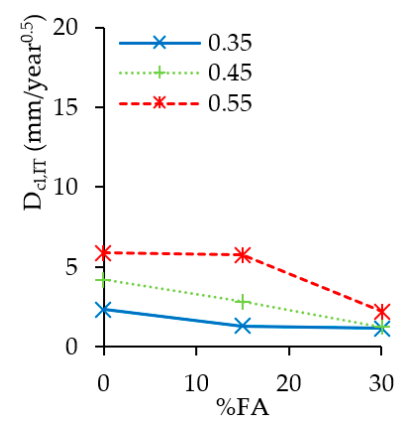

(b)

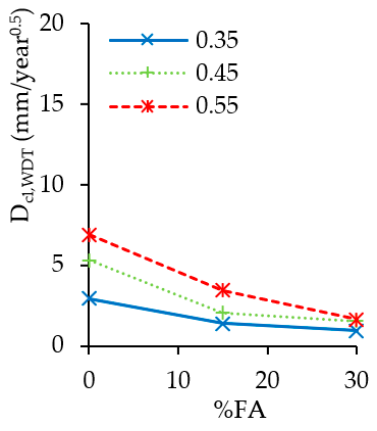

(e)

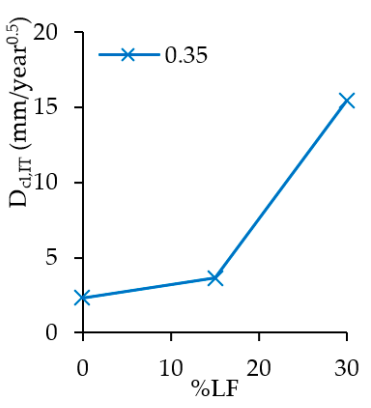

(c)

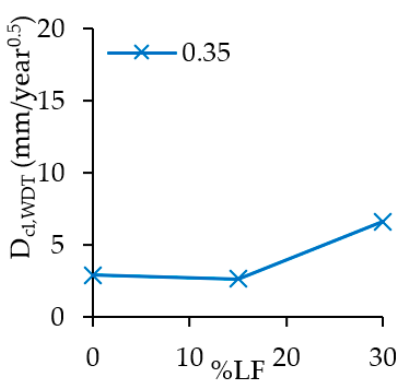

(f)

Figure 5. Chloride diffusion coefficient $D_{c l, I T}(\mathbf{a}-\mathbf{c})$ or $D_{c l, W D T}(\mathbf{d}-\mathbf{f})$ as a function of percentage incorporation of SF $(\mathbf{a}, \mathbf{d}), \mathrm{FA}(\mathbf{b}, \mathbf{e})$ and $\operatorname{LF}(\mathbf{c}, \mathbf{f})$. 


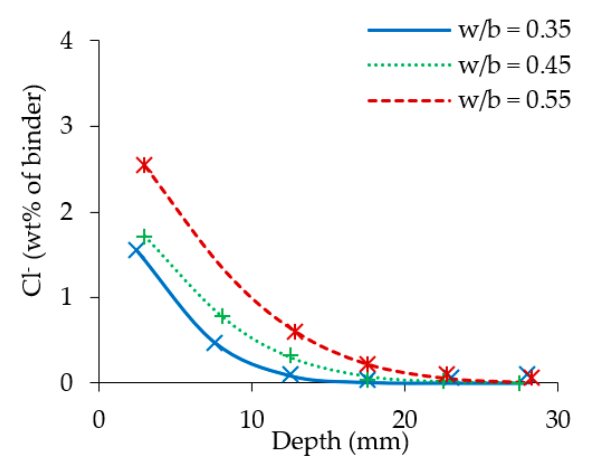

(a)

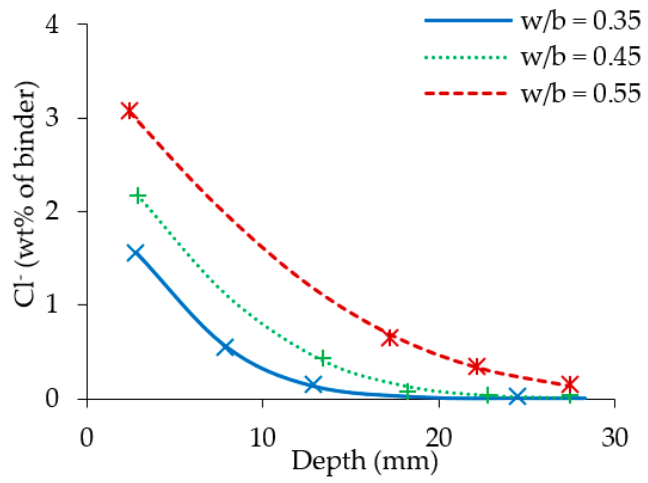

(b)

Figure 6. Chloride profiles of NWC with CEM I and different $\mathrm{w} / \mathrm{b}$, after being subjected to IT (a) and WDT conditions (b) for 3 months.

As expected, in long-term tests, the $D_{c l}$ increased with the $\mathrm{w} / \mathrm{b}$, regardless of the concrete composition, which demonstrates the major relevance of this parameter in the concrete microstructure. Therefore, the RCMT and the long-term tests showed to be sensitive to significant alterations in concrete microstructure, following the same trend regarding the classification of concrete quality.

Similarly to the RCMT, the incorporation of $6 \% \mathrm{SF}$ led to the reduction of the $D_{c l, I T}$ and the $D_{c l, W D T}$, respectively. Comparing to the RCMT, the reduction was of the same order of magnitude in the IT $(43.5 \%, 35.7 \%$ and $11.9 \%$ for $\mathrm{w} / \mathrm{b}$ of $0.35,0.45$ and 0.55 , respectively), confirming a greater contribution of SF in low $\mathrm{w} / \mathrm{b}$ concrete. In the WDT, where penetration may also be affected by absorption mechanisms, the incorporation of SF led to different reductions $(59 \%, 53 \%$ and $5.4 \%$ at $\mathrm{w} / \mathrm{b}$ of $0.35,0.45$ and 0.55 , respectively), although also higher in low $\mathrm{w} / \mathrm{b}$ concrete. In particular, concrete with high $\mathrm{w} / \mathrm{b}$ showed an abnormally high $D_{c l}$, which was even higher than that of concrete with only CEM I, indicating the low efficiency of the poorly dispersed SF.

Regarding the lower reactivity of FA, the long-term test results indicate an opposite trend than that of the RCMT. The increase of the incorporation percentage of FA led to a progressive reduction of the $D_{c l, I T}$ and the $D_{c l, W D T}$, confirming the greater efficiency of these additions at later ages. As mentioned, after 28 days, the slow pozzolanic reactions are more effective, creating a microstructure densification by capillary pore filling with additional hydration products. Moreover, the above-mentioned chloride binding properties are more significant in long-term tests. In these tests, the $D_{c l}$ tended to be lower in FA concrete than in SF concrete, especially for high $\mathrm{w} / \mathrm{b}$, which should be related with the poor dispersion and low chemical binding capacity of SF.

In general, as in the RCMT, the $D_{c l, I T}$ and $D_{c l, W D T}$ increased with the incorporation percentage of LF. The replacement of CEM I with this quasi-inert addition led to a reduction on both hydration products and aluminate content, coarsening the microstructure and reducing the chloride binding capacity. However, up to $15 \% \mathrm{LF}$ incorporation in low w/b concrete, the variation of $D_{c l}$ was not significant, for both the IT and the WDT. In this case, the filler and nucleation effects of LF could have partly compensated the slight reduction in hydration products and chloride binding capacity. For 30\%LF incorporation, $D_{c l, I T}$ presented an unexpectedly high value, which was not considered in further analysis.

The $K_{c r}$ as a function of $\mathrm{w} / \mathrm{b}$ and type of binder is presented in Figure 7, for the IT, $K_{c r, I T}$, and the WDT, $K_{c r, W D T}$. This parameter may provide a more detailed comparison of the concrete performance, since it also takes the surface chloride content, $C_{S}$, into account. However, the $C_{S}$ may vary between specimens due to variations in exposure conditions, justifying why $K_{c r}$ should not be analysed by itself. 


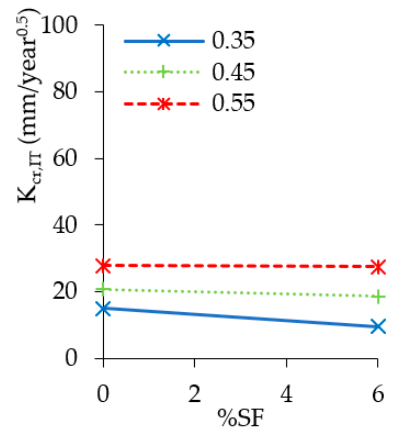

(a)

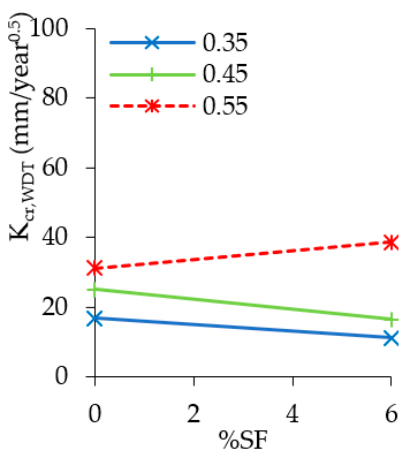

(d)

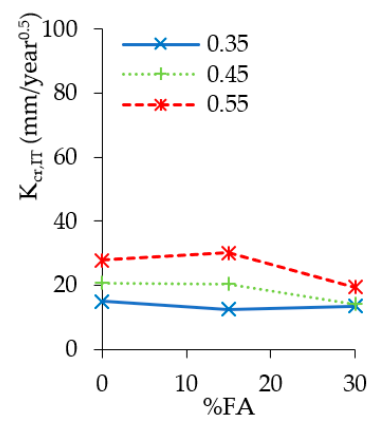

(b)

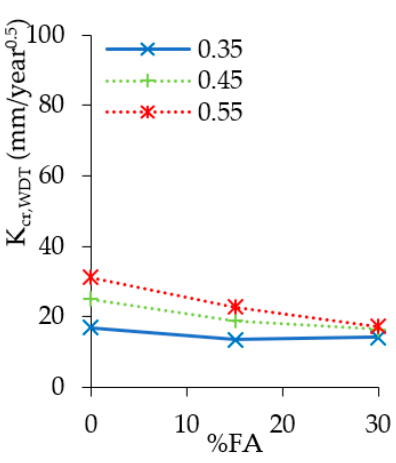

(e)

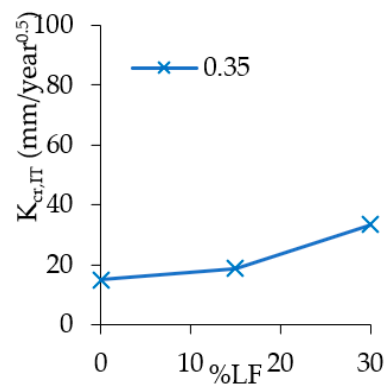

(c)

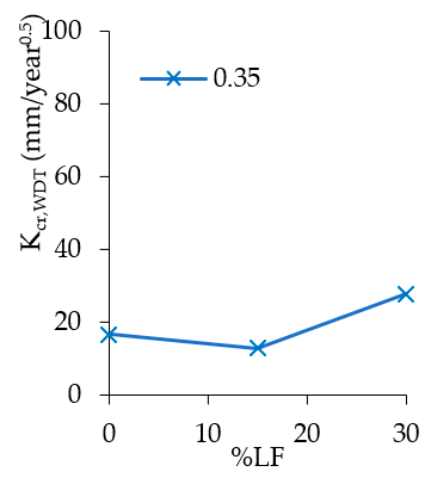

(f)

Figure 7. Penetration parameter $K_{c r, I T}(\mathbf{a}-\mathbf{c})$ or $K_{c r, W D T}(\mathbf{d}-\mathbf{f})$ as a function of percentage incorporation of SF (a,d), FA (b,e) and LF (c,f).

In general, the $C_{s, I T}$ was of the same order of magnitude of the $C_{s, W D T}$, although the latter tended to be slightly higher (Table 5). This may be related with the enhanced enrichment of chloride ions at the concrete surface caused by wetting-drying cycles [39,57,67-69]. This is in line with the higher $C_{s}$ usually reported in tidal zone than in submerged conditions $[39,52,70,71]$. However, as mentioned, in this study the WDT involved short drying periods, approximating the exposure conditions to those of IT. Additionally, note that the values of $C_{s}$ indicated in Table 5 are theoretically obtained from chloride profiles, which may deviate from the real $C_{s}$, especially in the WDT.

The $C_{S}$ increased with the $\mathrm{w} / \mathrm{b}$, as suggested in the literature $[53,72,73]$, since the porous surface structure may accommodate a higher chloride content [52,70]. Moreover, a systematic increase of $C_{S}$ with the incorporation percentage of FA was also observed (Table 5). This is related with the higher binding capacity of FA $[39,52,70]$. It is possible that the reduction of $D_{c l}$ in FA concrete also contribute to the greater retention of chloride ions at the concrete surface, as well as to the slightly higher volume of binder achieved after the weight replacement of CEM I with FA [52]. The minor variation of $C_{S}$ in SF concrete confirms the lower chloride binding capacity of these concretes compared to those with FA. In LF concrete, the trend was not clear, because the coarser microstructure and the lower chloride binding capacity have an opposite effect on $C_{s}$.

Due to the above mentioned aspects, the $K_{c r}$ increased with the $\mathrm{w} / \mathrm{b}$, since a coarser pore structure both contributed to the increase of the $C_{s}$ and the $D_{c l}$ (Figure 7). In general, the $K_{c r}$ followed the same trend of $D_{c l}$ in the IT and the WDT. However, the difference between these tests was higher in $K_{c r}$, because the $C_{s}$ tended to increase in the WDT.

Regarding the influence of the type of binder, the higher reduction of $D_{c l}$ was offset by the higher $C_{s}$ in FA concrete. Therefore, the evolution of $K_{c r}$ with the FA content was closer to that found in the RCMT. Nevertheless, the chloride penetration resistance increased with the incorporation percentage of FA. Since $C_{s}$ was less affected by SF and LF, in general, the same trend found in the $D_{c l}$ was maintained in the $K_{c r}$. 
The comparisons between the $D_{c l, I T}$ and the $D_{c l, R C M T}$, as well as the $D_{c l, W D T}$ and the $D_{c l, R C M T}$ are presented in Figure 8. In general, a poor correlation was observed between tests when all compositions were considered, regardless of the type of binder. As mentioned, the contribution of FA in the short duration RCMT was not as significant as in the long-term IT and WDT.

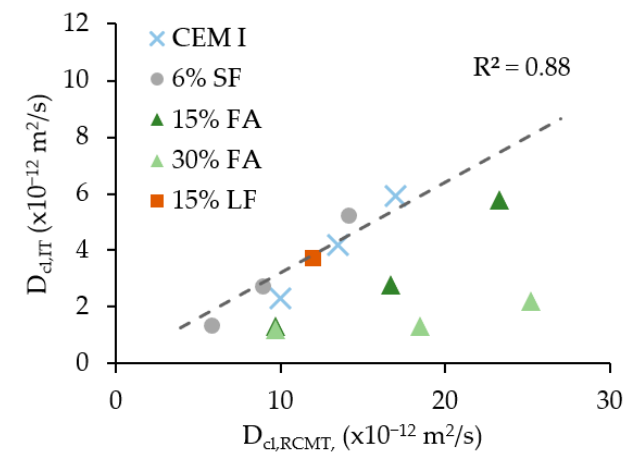

(a)

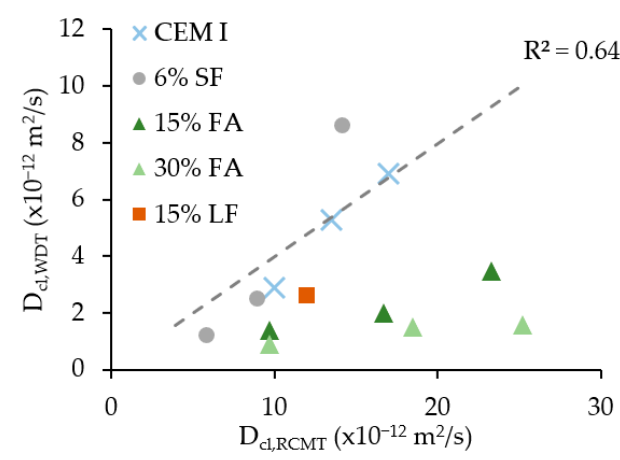

(b)

Figure 8. Comparison between $D_{c l, I T}(\mathbf{a})$ or $D_{c l, W D T}(\mathbf{b})$ and $D_{c l, R C M T}$.

However, when concretes with FA were excluded, the $D_{c l, I T}$ and the $D_{c l, W D T}$ followed the same trend of the $D_{c l, R C M T}$. Similar conclusions are reported in literature, when comparing the RCMT and the IT [5,35]. Despite the different test conditions the obtained correlation coefficient $\left(\mathrm{R}^{2}\right)$ was as high as 0.88 for the IT (Figure 8 ). However, for the WDT, the correlation was poorer, because for high $\mathrm{w} / \mathrm{b}$, the chloride penetration was more affected by the convection phenomenon. Therefore, when comparing these methods with distinct transport mechanisms, the correlation tends to be lower. Note that, for all correlations, the regression line was forced to cross the origin, maintaining the physical meaning of the analysis, which reduced the $\mathrm{R}^{2}$. Moreover, in Figure 8 , the concrete with FA appears to be clustered in the bottom of the plot, both for the IT and the WDT. This result emphasises the high efficiency of FA in increasing the chloride penetration resistance, as well as its slower reaction, only contributing to this property at later ages.

The relations between $K_{c r, I T}$ or $K_{c r, W D T}$ and $D_{c l, R C M T}$ are presented in Figure 9, taking into account all concretes with or without FA. As discussed, the mentioned impact of slower FA reactivity is mitigated when $\mathrm{Kcr}$ is considered instead of $D_{c l}$. Therefore, the difference between concrete with and without FA becomes smaller (Figure 9). Thus, the penetration parameter related better with $D_{c l, R C M T}$, especially when time-dependent additions were considered.

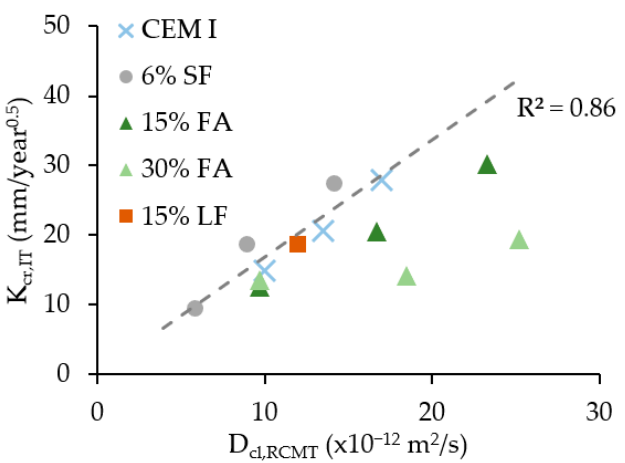

(a)

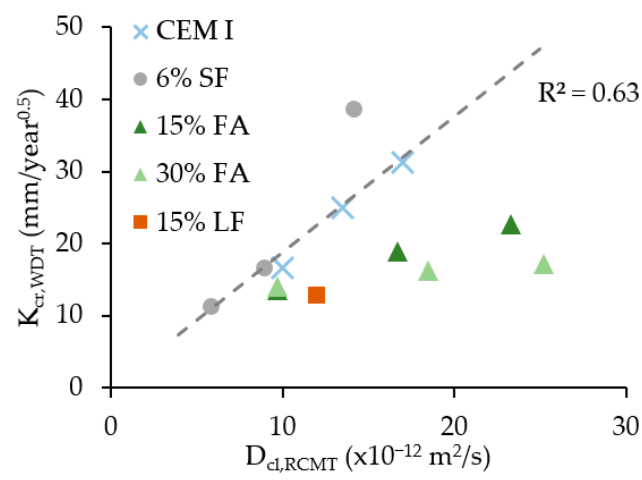

(b)

Figure 9. Comparison between $K_{c r, I T}(\mathbf{a})$ or $K_{c r, W D T}(\mathbf{b})$ and $D_{c l, R C M T}$.

Overall, results indicate that for NWC with distinct binders, the RCMT could reasonably characterise the chloride penetration resistance, having been able to sort concretes 
of different quality, in a wide range of low to high strength concrete. Although more time-consuming, the RCMT performed at 90 days would be more appropriate for concretes with slow reactive additions.

\subsection{Influence of the Type of Aggregate on the Chloride Penetration Resistance}

The variation of the $D_{c l, R C M T}$ with the $\mathrm{w} / \mathrm{b}$ for NWC and LWAC is presented in Figure 10. Although aggregates with very distinct porosities were considered, the $D_{c l, R C M T}$ was affected little by the type of aggregate. For concretes with similar composition, the maximum variability was lower than $15 \%$, which is under the maximum variability reported for this test [5]. The low influence of the type of LWA was also found by other authors, concluding that the chloride penetration resistance is mainly influenced by the paste quality [10,54-56]. However, LWAC with more porous LWA (Leca) showed slightly higher $D_{c l, R C M T}$ for all $\mathrm{w} / \mathrm{b}$. This may be related with the greater participation of LWA when saturated concrete is tested and chloride ions are allowed to migrate through continuous passes $[39,74]$. On the other hand, when concretes are allowed to dry and LWA are emptied by internal curing, their participation in chloride migration is decreased, especially in low $\mathrm{w} / \mathrm{b}$ concrete, where the aggregates are protected by a denser paste [54]. However, since the RCMT is performed in cut specimens, aggregates near the surface are more easily accessed and penetration becomes more relevant. In fact, in Figure 11, the participation of Leca in high $\mathrm{w} / \mathrm{b}$ concrete seems to have been slightly higher than in low w/b concrete. Nevertheless, according to the classification of Gjørv [33] (Table 1), the chloride penetration resistance of LWAC was comparable to that of NWC, being considered as concrete of moderate quality for $\mathrm{w} / \mathrm{b}$ up to 0.45 . The classification of Gjørv [33] was not able to distinguish the worse quality of LWAC with more porous aggregates in high $\mathrm{w} / \mathrm{b}$ concretes (Table 5). However, concretes with $\mathrm{w} / \mathrm{b}$ over 0.55 are not common in chloride exposure environments.

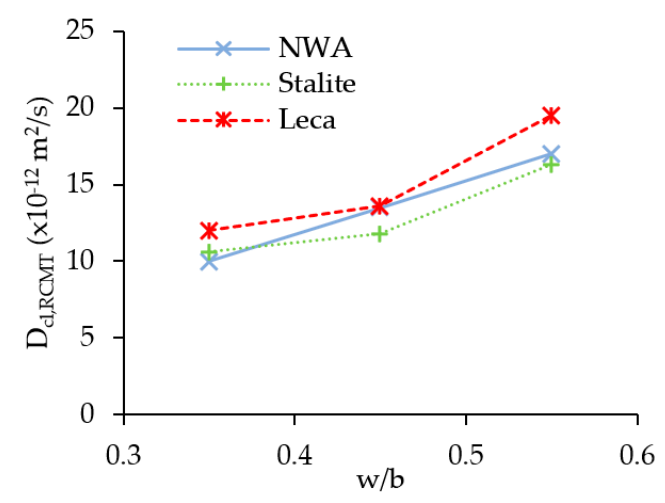

Figure 10. Chloride migration coefficient at 28 days, $D_{c l, R C M T}$, as a function of $\mathrm{w} / \mathrm{b}$.

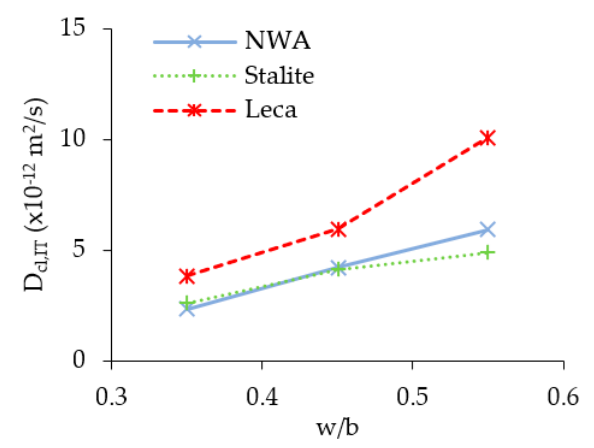

(a)

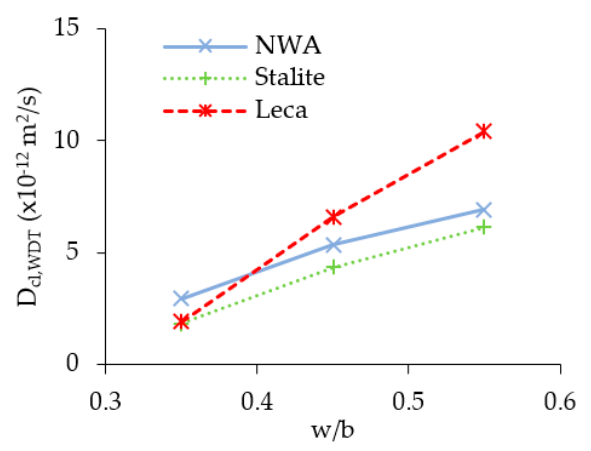

(b)

Figure 11. Chloride diffusion coefficient, $D_{c l, I T}(\mathbf{a})$ and $D_{c l, W D T}(\mathbf{b})$ as a function of $\mathrm{w} / \mathrm{b}$ (different types of aggregates). 
The results of the $D_{c l, I T}$ and the $D_{c l, W D T}$ taking into account different types of aggregates are presented in Figure 11. Contrary to other studies [52-54], the $D_{c l}$ was affected by the type of aggregate. In this case, LWAC with porous LWA always led to higher $D_{c l}$, confirming the trend of the RCMT.

This behaviour was more markedly observed in the IT (Figure 11a), because as discussed, if concretes are saturated the participation of porous aggregates becomes more evident, especially in high $\mathrm{w} / \mathrm{b}$ concrete. In fact, in these IT, concrete was kept saturated since their production, reducing the opportunity of LWA to release their water by internal curing. In this case, the high $\mathrm{w} / \mathrm{b}$ imply less dense pastes surrounding LWA and also a lower relevance of self-desiccation, and, hence, of the activation of the internal curing mechanism. Moreover, in high w/b concretes, LWA near the concrete surface are easily saturated by water permeability, which allow their participation in chloride diffusion. This phenomenon is more relevant in the present study, because penetration occurred perpendicular to the casting surface, where surface LWA were less protected by a mortar layer. The obtained results corroborate the study of Real et al. [39], concerning the monitorisation of different types of concrete exposed to real marine environment for 5 years. The authors found a lower chloride penetration resistance of LWAC than of NWC, during the first months of exposure, but the difference tended to be diluted over time, when inner concrete at greater depths were progressively involved. This is also in line with the results reported by Thomas and Bremner [73], indicating that LWAC and NWC presented similar chloride resistance, after 25 years of exposure to harsh marine environment.

In opposition, during the WDT, the concrete surface was allowed to dry, which promoted the partial emptying of the LWA. Then, the re-saturation of LWA and their effective participation in chloride penetration is more prone to occur in high $\mathrm{w} / \mathrm{b}$ matrixes with coarser microstructure and less protection capacity. Therefore, the differences between LWAC with more porous LWA and NWC were less noticeable in low $\mathrm{w} / \mathrm{b}$ concrete, up to $\mathrm{w} / \mathrm{b}$ of 0.45 (Figure $11 \mathrm{~b}$ ), but relevant in concrete with a w/b of 0.55 . Thus, the influence of the type of aggregate depended on the exposure conditions and paste composition.

Nevertheless, LWAC with denser LWA performed similarly to NWC, both in the IT and the WDT, regardless of the concrete composition. A slightly better behaviour of these concretes was even observed, for high $w / b$ concrete. One reason may be attributed to the improved interfacial transition zone (ITZ) usually observed in LWAC $[55,75]$.

The $K_{c r}$ of concrete with different types of aggregates is presented in Figure 12, for the IT and the WDT. The $C_{s}$ tended to be higher in LWAC with more porous LWA than in NWC and LWAC with denser aggregates (Stalite), both in the IT and the WDT (Table 5). The same behaviour was reported by other authors $[4,5,18,26,39]$. This is essentially attributed to the saturation of LWA at the concrete surface, retaining chlorides [76]. This contributed to a higher chloride penetration, increasing the $K_{c r}$ in LWAC with more porous LWA. For the same reasons mentioned above, this difference was more relevant in high $\mathrm{w} / \mathrm{b}$ concrete. In general, the increase of $D_{c l}$, combined with the higher $C_{s}$, led to a more significant influence of the type of aggregate on the $K_{c r}$, at least for short-term exposure tests, in which the influence of the concrete surface is more relevant. The lower value of $K_{c r}$ in LWAC with Leca and $\mathrm{a} \mathrm{w} / \mathrm{b}$ of 0.35 is explained by the unexpectedly low value of $C_{S}$ in this concrete (Table 5). In this case, the self-dissection could have partly emptied LWA, reducing both the $D_{c l}$ and the $C_{s}$. 


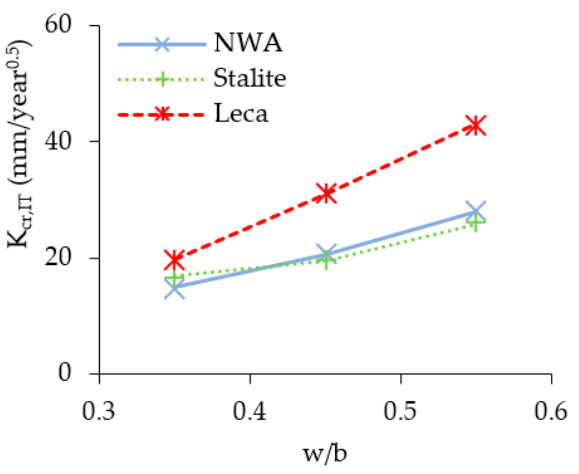

(a)

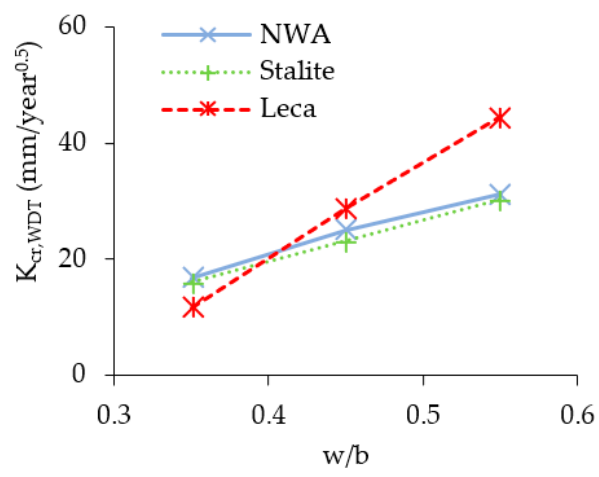

(b)

Figure 12. Penetration parameters $K_{c r, I T}(\mathbf{a})$ and $K_{c r, W D T}(\mathbf{b})$ as a function of $\mathrm{w} / \mathrm{b}$ (different types of aggregate).

Regarding LWAC with denser LWA, the influence on the $D_{c l}$ and on the $C_{s}$ was not significant and the $K_{c r}$ was similar to that of NWC, regardless of the $\mathrm{w} / \mathrm{b}$. The lowest values of the $K_{c r, W D T}$ in LWAC with denser LWA and high $\mathrm{w} / \mathrm{b}$ were motivated by the lowest $D_{c l, W D T}$ obtained in this concrete.

A reasonable trend was obtained between the $D_{c l, I T}$ and the $D_{c l, R C M T}$ (Figure 13), showing that the RCMT was able to adequately distinguish the $D_{c l}$ of concretes with different types of aggregate under long-term immersion exposure conditions. This is explained by the fact that both tests were performed in saturated exposure conditions. However, for the mentioned reasons, the greater participation of porous LWA in high $w / b$ concrete under IT reduced the correlation between tests. These differences were accentuated in the WDT, being justified, as mentioned, by the different exposure conditions that may promote a distinct participation of LWA near the concrete surface, affecting chloride penetration. As previously mentioned, $\mathrm{R}^{2}$ would be significantly higher, if regressions were not forced to cross the origin, but the physical meaning of the analysis would be distorted.

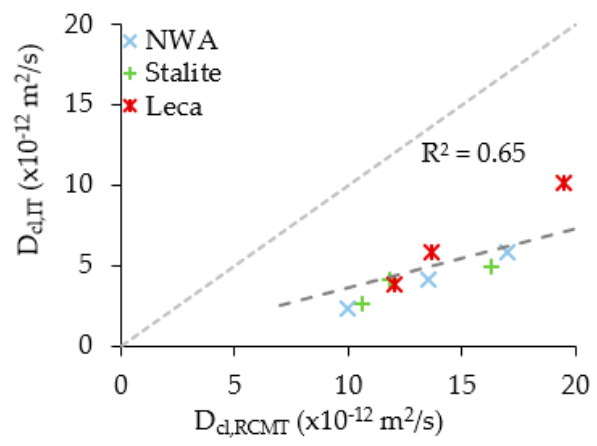

(a)

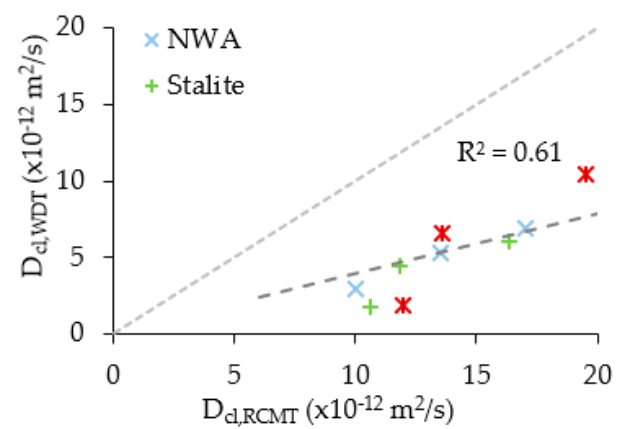

(b)

Figure 13. Comparison between $D_{c l, I T}(\mathbf{a})$ and $D_{c l, W D T}(\mathbf{b})$ with $D_{c l, R C M T}$ (different types of aggregate).

\subsection{Overview and Chloride Penetration Resistance Classification}

The comparisons between the $D_{c l, I T}$ and the $D_{c l, W D T}$ with the $D_{c l, R C M T}$ for all the concrete compositions considered in this study are presented in Figure 14. As discussed, regarding the influence of the type of binder (Section 3.1), a higher $\mathrm{R}^{2}$ was obtained between the $D_{c l}$ from different tests when concretes with FA incorporation were not considered (Figure 14). This confirms the slow-reactive nature of FA. Therefore, excluding concrete with FA, the RCMT performed at 28 days was able to sort concrete with distinct longterm chloride penetration behaviour, for concretes with different types of binder and aggregate. For concretes with high $\mathrm{w} / \mathrm{b}$ and porous LWA, the trend is diverted from the linear regression line (Figure 14). Therefore, the relation between tests was more adequate 
for concrete with $\mathrm{w} / \mathrm{b}$ up to 0.45 . Additionally, the $D_{c l, R C M T}$ varied through a wider range (about $25 \times 10^{-12} \mathrm{~m}^{2} / \mathrm{s}$ ) than both $D_{c l, I T}$ and $D_{c l, W D T}$ (about $10 \times 10^{-12} \mathrm{~m}^{2} / \mathrm{s}$ ), indicating a higher sensibility of the RCMT to diffusion coefficient variations caused by different concrete compositions than the IT or the WDT.

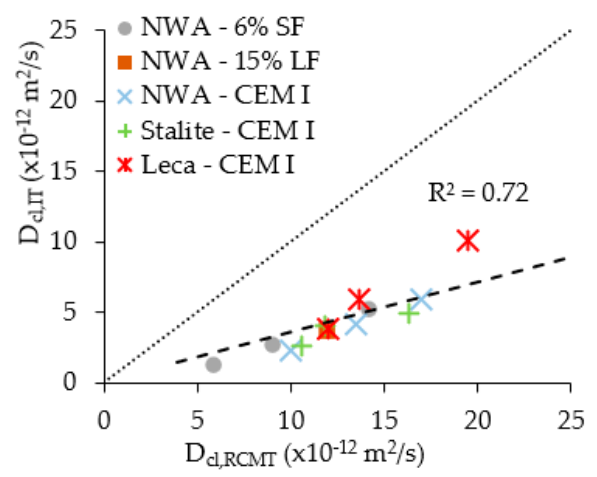

(a)

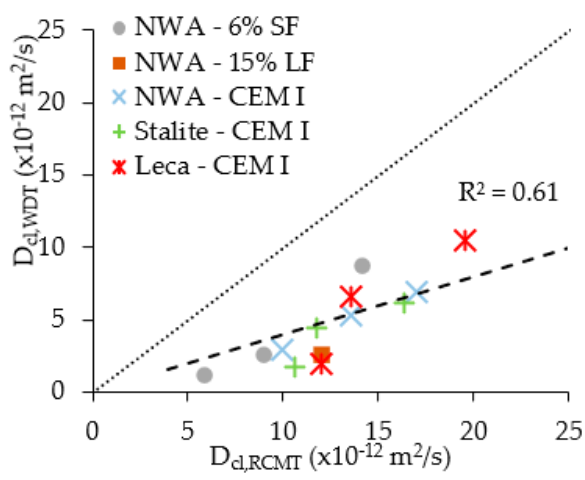

(b)

Figure 14. Comparison between $D_{c l, I T}(\mathbf{a})$ or $D_{c l, W D T}(\mathbf{b})$ and $D_{c l, R C M T}$ for all concrete compositions, except those with FA incorporation.

A higher $\mathrm{R}^{2}$ was found when the $D_{c l, R C M T}$ was correlated with the $K_{c r, I T}$ and the $K_{c r, W D T}$, as shown in Figure 15. This means that the RCMT was able to distinguish the chloride penetration resistance of concretes with different $w / b$, types of binder and types of aggregate of very distinct porosity. Comparing Figure 15 with Figure 9, in general, the type of aggregate had less influence on the relation between tests than the type of binder, since the $\mathrm{R}^{2}$ remained similar.

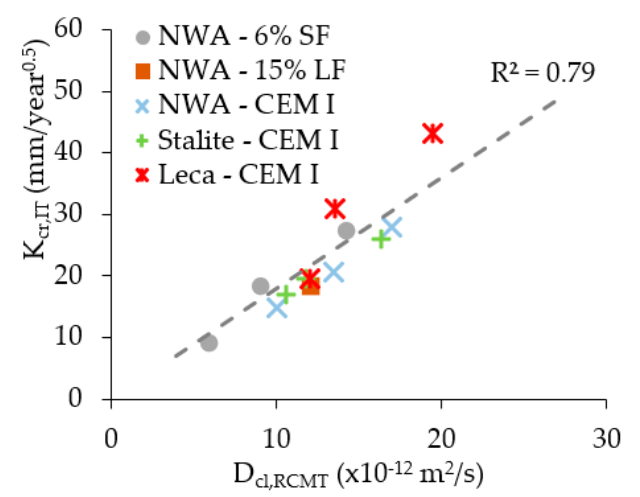

(a)

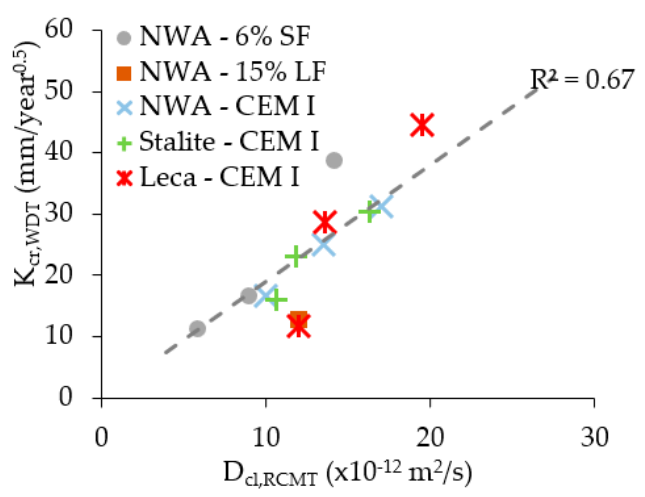

(b)

Figure 15. Comparison between $K_{c r, I T}(\mathbf{a})$ or $K_{c r, W D T}(\mathbf{b})$ and $D_{c l, R C M T}$ for all concrete compositions, except those with FA incorporation.

Contrarily to the comparison made with the $D_{c l, I T}$ and the $D_{c l, W D T}$ (Figure 14), the $D_{c l, R C M T}$ varied in a narrower range than the $K_{c r, I T}$ and the $K_{c r, W D T}$. Therefore, a small variation of the $D_{c l, R C M T}$ results in a more relevant change of the $K_{c r}$. However, as shown in Figure $16 \mathrm{a}$, in a small range, the variability between tests hinders a precise differentiation of concrete performance from the $D_{c l, R C M T}$. Indeed, despite the reasonable correlation between tests, the concrete performance did not always follow the same trend. For example, concrete with $6 \% \mathrm{SF}$ and a w/b of 0.55 presented a lower $D_{c l, R C M T}$ but a higher $K_{c r, W D T}$ and $D_{c l, W D T}$ than concrete with a w/b of 0.35 and $30 \%$ LF. This is explained by the different exposure and test conditions. Nevertheless, Figure $16 \mathrm{~b}$ shows a reasonable correlation between the $K_{c r, I T}$ and the $K_{c r, W D T}$, which, as mentioned, can be justified by the similar exposure test conditions. 


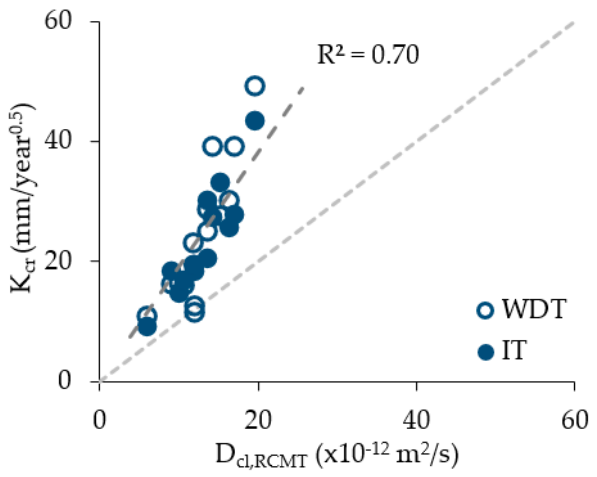

(a)

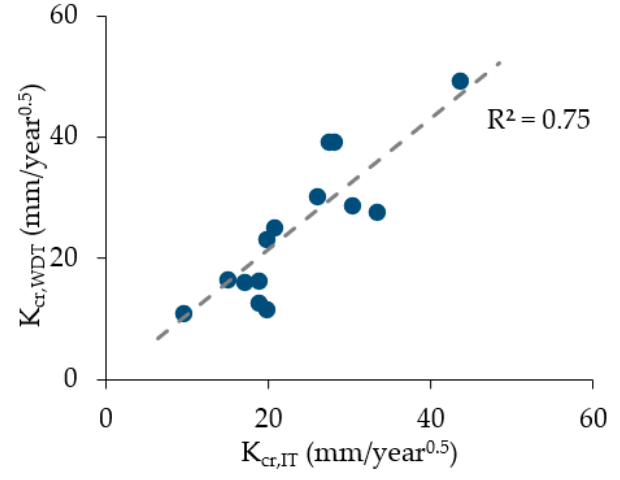

(b)

Figure 16. Comparison between the $K_{c r}$ and $D_{c l, R C M T}(\mathbf{a})$ and between $K_{c r, W D T}$ and $K_{c r, I T}(\mathbf{b})$.

Based on the results obtained in this study, concretes with different levels of $D_{c l, R C M T}$ fell within the ranges of $K_{c r, I T}$ and $K_{c r, W D T}$ indicated in Figure 17. As a small variation of the $D_{c l, R C M T}$ may lead to a relevant change of the $K_{c r}$, compared to the classification of Gjørv [33], narrower ranges stepped by $2.5 \times 10^{-12} \mathrm{~m}^{2} / \mathrm{s}$ were considered in ranking the concrete chloride penetration resistance. The classification classes were extended to cover a wider set of low to high quality concretes.

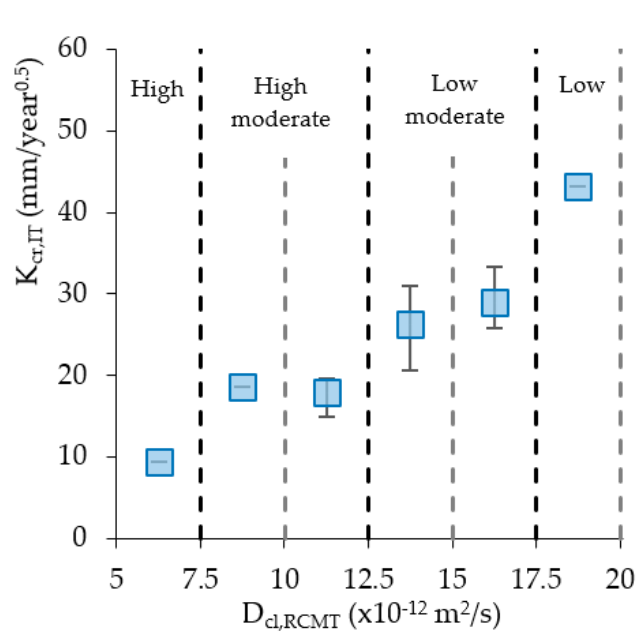

(a)

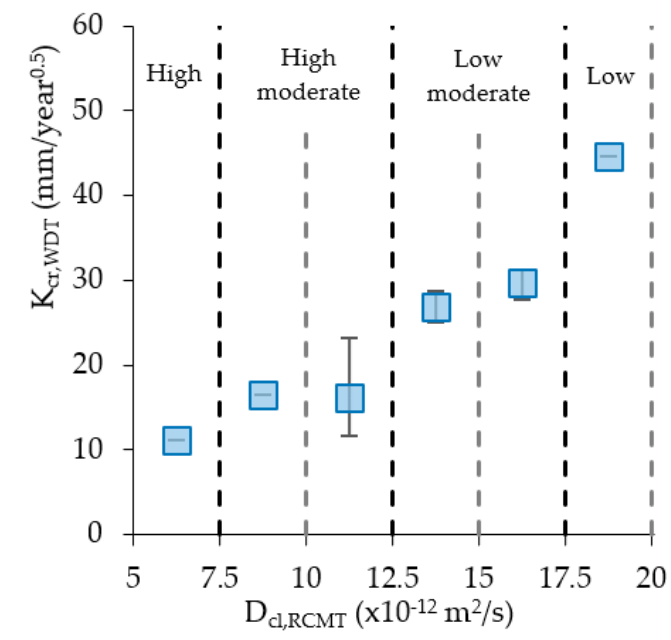

(b)

Figure 17. Classification of chloride penetration resistance from $D_{c l, R C M T}$, based on $K_{c r, I T}(\mathbf{a})$ and $K_{c r, W D T}(\mathbf{b})$.

As discussed, a small variation of $D_{c l, R C M T}$ may correspond to a relevant change of the $K_{c r}$. Therefore, the defined classes overlap in some ranges, so that concretes of different grades may present similar or even an opposite chloride penetration resistance to that suggested from RCMT classes (Figure 17). Nevertheless, the division in various RCMT classes was able to distinguish concretes with significant differences of chloride penetration resistance, based on $K_{c r}$. Except for FA concrete, the same ranking of concrete chloride penetration resistance obtained from RCMT was generally maintained after performing long-term tests simulating real exposure conditions. The high quality class includes concrete with SF and $\mathrm{w} / \mathrm{b}$ up to 0.45 . On the other hand, concretes with high incorporation of LF or high $\mathrm{w} / \mathrm{b}(0.55)$ are within the low quality class. The classification was affected little by the type of aggregate. A significant overlapping between RCMT classes is observed in the ranges 7.5-12.5 and 12.5-17.5 $\left(\times 10^{-12} \mathrm{~m}^{2} / \mathrm{s}\right)$, suggesting that these classes may be merged, both in the IT and the WDT. Therefore, taking into account Figure 17, and comparing to the classification of Gjørv [33] (Table 1), a clearer distinction between concrete 
performance is obtained for the following classes $\left(\times 10^{-12} \mathrm{~m}^{2} / \mathrm{s}\right): 5-7.5 ; 7.5-12.5 ; 12.5-17.5$; $>17.5$. However, further research is needed to cover a wider sample, especially in the range of high quality concretes, up to $10 \times 10^{-12} \mathrm{~m}^{2} / \mathrm{s}$.

The same procedure was carried out regarding the analysis of the $D_{c l, I T}$ and $D_{c l, W D T}$ ranges within the same RCMT classes (Figure 18). For the above-mentioned reasons, concrete with $30 \%$ LF was excluded from the IT results. Overlapping is also observed in concretes of different RCMT grades. However, the RCMT could reasonably sort concrete with different chloride diffusion properties when the classes 7.5-10 and 10-12.5 $\left(\times 10^{-12} \mathrm{~m}^{2} / \mathrm{s}\right)$, as well as $12.5-15$ and $15-17.5\left(\times 10^{-12} \mathrm{~m}^{2} / \mathrm{s}\right)$, were merged. The same classes suggested based on the $K_{c r}$ showed to be also adequate when based on the $D_{c l}$.

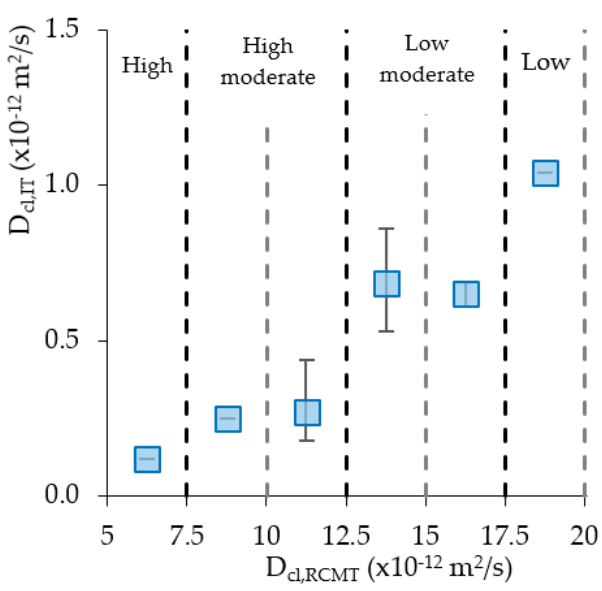

(a)

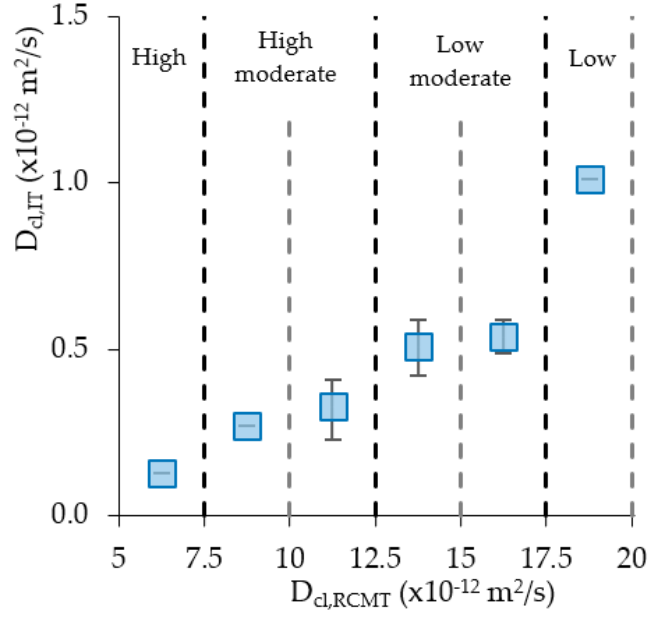

(b)

Figure 18. Classification of chloride penetration resistance from $D_{c l, R C M T}$, based on $D_{c l, I T}(\mathbf{a})$ and $D_{c l, W D T}(\mathbf{b})$.

Overall, from the results obtained in this study, covering low to high strength concrete produced with different types of binder and aggregate, despite some identified differences, the RCMT could follow the same trend of the long-term IT and WDT, regarding the classification of the chloride penetration resistance of concrete.

\section{Conclusions}

In this paper, the efficiency of the RCMT in assessing the chloride penetration resistance of concrete under submerged or wetting and drying conditions was analysed for a wide range of concretes with different $\mathrm{w} / \mathrm{b}$, types of aggregate and types and amounts of binder. To this end, the RCMT results were compared to those from the long-term IT and WDT, simulating real exposure conditions. This study covered a wide range of common NWC and LWAC for strength classes C20/25-C60/75 and LC20/22-LC60/66, respectively, which presented $D_{c l, R C M T}$ of $6-25 \times 10^{-12} \mathrm{~m}^{2} / \mathrm{s}$, representative of low to high chloride penetration resistance.

The $\mathrm{w} / \mathrm{b}$ was the most influential parameter in the chloride penetration resistance, regardless of the type of binder and aggregate. The RCMT and long-term tests were able to distinguish in the same manner significant alterations introduced by $\mathrm{w} / \mathrm{b}$ in the concrete microstructure, following the same trend in the classification of concrete quality.

Regarding the influence of the type of binder, a reasonable relation between the RCMT and the long-term tests was only achieved when concrete with FA was not considered. The incorporation of SF improved the chloride penetration resistance significantly from an early age, especially in low $\mathrm{w} / \mathrm{b}$ concretes. The opposite behaviour was found with the incorporation of the quasi-inert LF. The same trends were found in both the RCMT and the long-term tests. However, the incorporation of FA was only effective in increasing 
the chloride penetration resistance of concrete under long-term tests, where the chloride binding effect and the slow pozzolanic reactions were more relevant. Regarding the longterm tests, the reduction of $D_{c l}$ was partly offset by the higher $C_{s}$ in FA concrete. The RCMT carried out at 28 days showed to be inadequate in assessing the contribution of this addition in natural exposure conditions. Although more time-consuming, the RCMT at 90 days are recommended for FA concrete.

In general, the $D_{c l}$ was affected little by the type of aggregate. However, for LWAC with porous LWA and high $\mathrm{w} / \mathrm{b}$, the $D_{c l}$ was higher, both in the RCMT and the longterm tests. The saturation conditions of surface LWA in long-term tests allowed their greater participation in chloride penetration. This participation was higher in the IT than in the WDT, because concretes were not allowed to dry since their production date. The differences between NWC and LWAC with porous LWA tended to be higher when the RCMT was related with $K_{c r}$, because the $C_{s}$ increased with the aggregate porosity in high $\mathrm{w} / \mathrm{b}$ concrete. This confirmed the lower chloride penetration resistance of LWA with porous aggregates under short-exposure conditions. Noteworthy was the similar to better performance of LWAC with dense LWA compared to NWC, regardless of the concrete composition and exposure conditions.

Similarly to the IT, for low $\mathrm{w} / \mathrm{b}$ concrete, the $D_{c l}$ was the predominant mechanism in the WDT. The WDT involved short-drying cycles, approximating to the exposure conditions of the IT. However, in high $\mathrm{w} / \mathrm{b}$ concrete, the convection phenomenon was more relevant and the calculated $D_{c l}$ tended to be higher in the WDT than in the IT. The difference between these tests was higher in $K_{c r}$, because the $C_{s}$ tended to increase in WDT.

At least under the different exposure conditions considered in this study, reasonable correlations were obtained between the $D_{c l, R C M T}$ and the $D_{c l}$ or the $K_{c r}$ from long-term tests, except for NWC with FA or LWAC with porous LWA and a w/b over 0.45 . The correlation was higher between the $D_{c l, R C M T}$ and the $K_{c r}$ which is directly related with the chloride penetration resistance of concrete. The type of aggregate had less influence on the relation between tests than the type of binder. The RCMT and the WDT, which involved different penetration mechanisms, showed a poorer correlation.

Based on the results of this study the chloride penetration resistance of concrete was sorted into recommended RCMT classes, which are able to distinguish concretes of different quality. In general, the same ranking of chloride penetration resistance suggested from $D_{c l, R C M T}$ was valid for $D_{c l}$ and $K_{c r}$, from both long-term tests considered in this study. However, further research is needed, especially in the range of high quality concretes.

In general, the RCMT was a reasonable indicator of the chloride penetration resistance of concrete, having been able to distinguish concrete produced with different types of aggregate and paste compositions, under distinct long-term exposure conditions.

Author Contributions: Conceptualisation, J.P., J.A.B. and S.R.; methodology, J.P., J.A.B. and S.R.; software, J.P.; validation, J.P., J.A.B. and S.R.; formal analysis, J.P., J.A.B. and S.R.; investigation, J.P., J.A.B. and S.R.; resources, J.P., J.A.B. and S.R.; data curation, J.P., J.A.B. and S.R.; writingoriginal draft preparation, J.P., J.A.B., S.R. and A.S.; writing—review and editing, J.P., J.A.B. and S.R.; funding acquisition, J.P. and J.A.B. All authors have read and agreed to the published version of the manuscript.

Funding: This research was funded by the Portuguese Foundation for Science and Technology (FCT), through scholarship SFRH/BD/111278/2015.

Institutional Review Board Statement: Not applicable.

Informed Consent Statement: Not applicable.

Data Availability Statement: Not applicable.

Acknowledgments: The first author wishes to thank the financial support of the Portuguese Foundation for Science and Technology (FCT), through scholarship SFRH/BD/111278/2015. The authors wish to acknowledge CERIS/IST for supporting the research, and the companies SECIL, Central 
Termoelétrica do Pêgo, Saint-Gobain Weber Portugal, Stalite, and BASF for supplying the materials used in the experiments.

Conflicts of Interest: The authors declare no conflict of interest.

\section{References}

1. Stanish, K.D.; Hooton, R.D.; Thomas, M.D.A. Testing the Chloride Penetration Resistance of Concrete: A Literature Review. In FHWA Contract DTFH61-97-R-00022 Prediction of Chloride Penetration in Concrete; Department of Civil Engineering, University of Toronto: Toronto, ON, Canada, 1997. Available online: https://rosap.ntl.bts.gov/view/dot/35971 (accessed on 21 July 2021).

2. Geiker, M.; Grube, H.; Luping, T.; Nilsson, L.O.; Andrade, C. Laboratory test methods. In Rilem Report 12: Performance Criteria for Concrete Durabilitity; Kropp, J., Hilsdorf, H.K., Eds.; CRC Press: Boca Raton, FL, USA, 1995.

3. Li, L.Y.; Easterbrook, D.; Xia, J.; Jin, W.L. Numerical simulation of chloride penetration in concrete in rapid chloride migration tests. Cem. Concr. Compos. 2015, 63, 113-121. [CrossRef]

4. Yuan, Q.; De Schutter, G.; Shi, C.; Audenaert, K. The relationship between chloride diffusion and migration coefficients in concrete In Proceedings of the International Conference on Microstructure Related Durability of Cementitious Composites, Nanjing, China, 13-15 October 2008; pp. 553-563. Available online: http:/ / hdl.handle.net/1854/LU-664061 (accessed on 21 July 2021).

5. Chlortest. Guideline for Practical Use of Methods for Testing the Resistance of Concrete to Chloride Ingress. Chlortest-EU Funded Research Project Under 5 FP Growth Programe. Resistance of Concrete to Chloride Ingress from Tests to In-Field Performance. Prepared by Tang Luping, 2005. Available online: http://www.civil.ist.utl.pt/ \{\}cristina/RREst/Aulas_ Apresentacoes/07_Bibliografia/durabilidade\%20betao\%20\%28durability\%29/Outros/Guidline $\% 20$ different $\% 20$ method $\% 20$ choloride\%20ingress.pdf (accessed on 21 July 2021).

6. Andrade, C. Calculation of chloride diffusion coefficients in concrete from ionic migration measurements. Cem. Concr. Res. 1993, 23, 724-742. [CrossRef]

7. Streicher, P.E.; Alexander, M.G. A chloride conduction test for concrete. Cem. Concr. Res. 1995, 25, 1284-1294. [CrossRef]

8. Basheer, L.; Kropp, J.; Cleland, D.J. Assessment of the durability of concrete from its permeation properties: A review. Constr. Build. Mater. 2001, 15, 93-103. [CrossRef]

9. Junior, J.R.H.; Balestra, C.E.T.; Medeiros-Junior, R.A. Comparison of test methods to determine resistance to chloride penetration in concrete: Sensitivity to the effect of fly ash. Constr. Build. Mater. 2021, 277, 122265. [CrossRef]

10. Bogas, J.A.; Gomes, A. Non-steady-state accelerated chloride penetration resistance of structural lightweight aggregate concrete. Cem. Concr. Compos. 2015, 60, 111-122. [CrossRef]

11. Chia, K.S.; Zhang, M.H. Water permeability and chloride penetrability of high-strength lightweight aggregate concrete. Cem. Concr. Res. 2002, 32, 639-645. [CrossRef]

12. Nilsson, L.-O.; Poulsen, E.; Sandberg, P.; Sørensen, H.E.; Klinghoffer, O. HETEK, Chloride Penetration into Concrete, State-of-theArt. Transport Processes, Corrosion Initiation, Test Methods and Prediction Models. HETEK Report No. 53. Denmark, The Danish Road Directorate, 1996. Available online: https:/ / www.researchgate.net/publication/264420368_HETEK_Chloride_penetration_ into_concrete_State-of-the-Art_Transport_processes_corrosion_initiation_test_methods_and_prediction_models (accessed on 21 July 2021).

13. Tang, L.; Nilsson, L.-O.; Basheer, P.A.M. Resistance of Concrete to Chloride Ingress; CRC Press: London, UK, 2011. [CrossRef]

14. Park, B.; Jang, S.Y.; Cho, J.Y.; Kim, J.Y. A novel short-term immersion test to determine the chloride ion diffusion coefficient of cementitious materials. Constr. Build. Mater. 2014, 57, 169-178. [CrossRef]

15. Zofia, S.; Adam, Z. Theoretical model and experimental tests on chloride diffusion and migration processes in concrete. Procedia Eng. 2013, 57, 1121-1130. [CrossRef]

16. Whiting, D. Rapid Measurement of the Chloride Permeability of Concrete. FHWA-RD-81-119 Final Rpt., FCP 34K1-012, Washington, USA. 1981. Available online: https:/ / trid.trb.org/view/171158 (accessed on 21 July 2021).

17. AASHTO. Standard Method of Test for Electrical Indication of Concrete's Ability to Resist Chloride Ion Penetration; AASHTO T 277; American Association of State and Highway Transportation Officials (AASHTO): Washington, WA, USA, 2019.

18. ASTM. Standard Test Method for Electrical Indication of Concrete's Ability to Resist Chloride Ion Penetration; ASTM C1202; American Society for Testing \& Materials (ASTM): West Conshohocken, PA, USA, 2012.

19. Wee, T.H.; Suryavanshi, A.K.; Tin, S.S. Evaluation of rapid chloride permeability test (RCPT) results for concrete containing mineral admixtures. ACI Struct. J. 2000, 97, 221-232. [CrossRef]

20. Papadakis, V.G. Effect of supplementary cementing materials on concrete resistance against carbonation and chloride ingress. Cem. Concr. Res. 2000, 30, 291-299. [CrossRef]

21. de Schutter, G.; Ye, G.; Audenaert, K.; Bager, D.; Baroghel-Bouny, V.; Bellmann, F.; Boel, V.; Bonen, D.; Boström, L.; Corradi, M.; et al. Final report of RILEM TC 205-DSC: Durability of self-compacting concrete. Mater. Struct. Constr. 2008, 41, $225-233$. [CrossRef]

22. Samson, E.; Marchand, J.; Snyder, K.A. Calculation of ionic diffusion coefficients on the basis of migration test results. Mater. Struct. Constr. 2003, 36, 156-165. [CrossRef]

23. Luping, T. Chloride Transport in Concrete-Measurement and Prediction. Ph.D. Thesis, Department of Building Materials, Chalmers University of Technology, Gothenburg, Sweden, 1996. Available online: https://research.chalmers.se/en/publication/ 1267 (accessed on 21 July 2021). 
24. Nordtest Method. Concrete, Mortar and Cement-based Repair Materials: Chloride Migration Coefficient from Non-Steady-State Migration Experiments; NT Build 492; Nordtest Method: Helsinki, Finland, 1999.

25. Spiesz, P.; Brouwers, H.J.H. Analysis of the Rapid Chloride Migration test. In Proceedings of the 3rd International PhD Workshop on Modelling the Durability of Reinforced Concrete, Guimaraes, Portugal, 22-24 October 2009; Ferreira, A.C., Gulikers, R.M., Eds.; RILEM Publications SARL: Guimarães, Portugal, 2009.

26. Spiesz, P.; Ballari, M.M.; Brouwers, H.J.H. RCM: A new model accounting for the non-linear chloride binding isotherm and the non-equilibrium conditions between the free- and bound-chloride concentrations. Constr. Build. Mater. 2012, 27, 293-304. [CrossRef]

27. CUR. The European Union-Brite EuRam III. Probabilistic Performance based Durability Design of Concrete Structures. In Duracrete Final Technical Report; Document BE95-1347/R17; CUR: Gouda, The Netherlands, 2000.

28. Spiesz, P.; Brouwers, H.J.H. Influence of the applied voltage on the Rapid Chloride Migration (RCM) test. Cem. Concr. Res. 2012, 42, 1072-1082. [CrossRef]

29. Jiang, L.; Song, Z.; Yang, H.; Pu, Q.; Zhu, Q. Modeling the chloride concentration profile in migration test based on general Poisson Nernst Planck equations and pore structure hypothesis. Constr. Build. Mater. 2013, 40, 596-603. [CrossRef]

30. Marchand, J.; Samson, E. Predicting the service-life of concrete structures-Limitations of simplified models. Cem. Concr. Compos. 2009, 31, 515-521. [CrossRef]

31. FIB. Model Code for Service Life Design-Bulletin 34; Prepared by Task Group 5.6: Model code for service life design of concrete structures; Fédération Internationale du Béton (FIB): Lausanne, Switzerland, 2006.

32. LNEC Specification. Concrete: Methodology for Estimating the Concrete Performance Properties Allowing to Comply with the Design Working Life of the Reinforced or Prestressed Concrete Structures under the Environmental Exposures XC and XS; LNEC Specification: Lisboa, Portugal, 2007.

33. Gjørv, O.E. Performance and serviceability of concrete structures in the marine environment. In Proceedings of the Odd E. Gjørv Symposium on Concrete for Marine Structures, CANMET/ACI, Ottawa, ON, Canada, 4-9 August 1996.

34. Spiesz, P.; Brouwers, H.J.H. Evaluation of the rapid chloride migration ( $\mathrm{rcm}$ ) test. In Proceedings of the 3rd International PhD Workshop on Modelling the Durability of Reinforced Concrete, Weimar, Germany, 23-26 September 2009.

35. Tang, L.; Sørensen, H.E. Precision of the Nordic test methods for measuring the chloride diffusion/migration coefficients of concrete. Mater. Struct. Constr. 2001, 34, 479-485. [CrossRef]

36. Jen, G.; Stompinis, N.; Jones, R. Chloride ingress in a belite-calcium sulfoaluminate cement matrix. Cem. Concr. Res. 2017, 98, 130-135. [CrossRef]

37. NT Build 443. Concrete Hardened: Accelerated Chloride Penetration; Nordtest Method: Helsinki, Finland, 1995.

38. Frederiksen, M.; Andersen, A.; Klinghoffer, O. The effect of the w/c ratio on chloride transport into concrete: Immersion, migration, and resistivity tests. HETEK Danish Road Dir. 1997. [CrossRef]

39. Real, S.; Bogas, J.A.; Pontes, J. Structural lightweight aggregate concrete exposed to marine environment for 5 years. Constr. Build. Mater. 2021, 275, 122161. [CrossRef]

40. Bogas, J.A.; Real, S. A review on the carbonation and chloride penetration resistance of structural lightweight aggregate concrete. Materials 2019, 12, 3456. [CrossRef] [PubMed]

41. LNEC. Concrete: Prescriptive Methodology for a Design Working Life of 50 Years under the Environmental Exposure; LNEC specification: Lisboa, Portugal, 2007.

42. CEN. Cement Part 1: Composition, Specifications and Conformity Criteria for Common Cements; EN 197-1; European Committee for standardization (CEN): Brussels, Belgium, 2011.

43. CEN. Testing Hardened Concrete. Density of Hardened Concrete; EN 12390-7; European Committee for standardization (CEN): Brussels, Belgium, 2009.

44. CEN. Testing Hardened Concrete. Compressive Strength of Test Specimens; EN 12390-3; European Committee for standardization (CEN): Brussels, Belgium, 2009.

45. LNEC. Concrete: Determination of Chloride Penetration Resistance. Immersion Test; LNEC Specification: Lisboa, Portugal, 1993.

46. Kropp, J. Relations between transport characteristics and durability. In Rilem Report 12: Performance Criteria for Concrete Durabilitity; Kropp, J., Hilsdorf, H.K., Eds.; CRC Press: Boca Raton, FL, USA, 1995.

47. Otieno, M.; Beushausen, H.; Alexander, M. Chloride-induced corrosion of steel in cracked concrete - Part I: Experimental studies under accelerated and natural marine environments. Cem. Concr. Res. 2016, 79, 373-385. [CrossRef]

48. Lu, C.; Gao, Y.; Cui, Z.; Liu, R. Experimental analysis of chloride penetration into concrete subjected to drying-wetting cycles. J. Mater. Civ. Eng. 2015, 27, 04015036. [CrossRef]

49. Hong, K.; Hooton, R.D. Effects of cyclic chloride exposure on penetration of concrete cover. Cem. Concr. Res. 2002, 29, 1379-1386. [CrossRef]

50. CEN. Concrete: Specification, Performance, Production and Conformity; EN 206; European Committee for standardization (CEN): Brussels, Belgium, 2013.

51. AASHTO. Sampling and Testing for Chloride Ion in Concrete and Concrete Raw Materials; AASHTO T 260-97; American Association of State and Highway Transportation Officials (AASHTO): Washington, WA, USA, 2011.

52. Real, S.; Bogas, J.A. Chloride ingress into structural lightweight aggregate concrete in real marine environment. Mar. Struct. 2018, 61, 170-187. [CrossRef] 
53. Bogas, J. Characterization of Structural Lightweight Expanded Clay Aggregate Concrete. Ph.D. Thesis, Instituto Superior Técnico, Universidade de Lisboa, Lisboa, Portugal, 2011.

54. Real, S.; Bogas, J.A.; Pontes, J. Chloride migration in structural lightweight aggregate concrete produced with different binders. Constr. Build. Mater. 2015, 98, 425-436. [CrossRef]

55. Liu, X.; Chia, K.S.; Zhang, M.H. Water absorption, permeability, and resistance to chloride-ion penetration of lightweight aggregate concrete. Constr. Build. Mater. 2011, 25, 335-343. [CrossRef]

56. Naito, C.; Fox, J.; Bocchini, P.; Khazaali, M. Chloride migration characteristics and reliability of reinforced concrete highway structures in Pennsylvania. Constr. Build. Mater. 2020, 231, 117045. [CrossRef]

57. Thomas, M.D.A.; Bamforth, P.B. Modelling chloride diffusion in concrete effect of fly ash and slag. Cem. Concr. Res. 1999, 29, 487-495. [CrossRef]

58. Youm, K.S.; Moon, J.; Cho, J.Y.; Kim, J.J. Experimental study on strength and durability of lightweight aggregate concrete containing silica fume. Constr. Build. Mater. 2016, 114, 517-527. [CrossRef]

59. Khayat, K.H.; Vachon, M.; Lanctôt, M.C. Use of blended silica fume cement in commercial concrete mixtures. ACI Mater. J. 1997, 94, 183-192. [CrossRef]

60. Pontes, J.; Santos Silva, A.; Faria, P. Evaluation of Pozzolanic Reactivity of Artificial Pozzolans. Mater. Sci. Forum. 2012, 730-732, 433-438. [CrossRef]

61. Hansen, T.C. Long-term strength of high fly ash concretes. Cem. Concr. Res. 1990, 20, 193-196. [CrossRef]

62. Liu, J.; Wang, X.; Qiu, Q.; Ou, G.; Xing, F. Understanding the effect of curing age on the chloride resistance of fly ash blended concrete by rapid chloride migration test. Mater. Chem. Phys. 2017, 196, 315-323. [CrossRef]

63. Argiz, C.; Moragues, A.; Menéndez, E. Use of ground coal bottom ash as cement constituent in concretes exposed to chloride environments. J. Clean. Prod. 2018, 170, 25-33. [CrossRef]

64. Cyr, M.; Lawrence, P.; Ringot, E. Efficiency of mineral admixtures in mortars: Quantification of the physical and chemical effects of fine admixtures in relation with compressive strength. Cem. Concr. Res. 2006, 36, 264-277. [CrossRef]

65. Skibsted, J.; Snellings, R. Reactivity of supplementary cementitious materials (SCMs) in cement blends. Cem. Concr. Res. 2019, 124, 105799. [CrossRef]

66. Real, S. Durability and thermal performance of structural lightweight aggregate concrete produced with different types of cementitious materials. Ph.D. Thesis, Instituto Superior Técnico, Universidade de Lisboa, Lisbon, Portugal, 2019.

67. Bertolini, L.; Polder, R. Corrosion of Steel in Concrete: Prevention, Diagnosis, Repair; Wiley Online Library; John Wiley \& Sons: Hoboken, NJ, USA, 2005; Available online: https:/ / onlinelibrary.wiley.com/doi/book/10.1002/3527603379 (accessed on 21 July 2021).

68. Safehian, M.; Ramezanianpour, A.A. Prediction of RC structure service life from field long term chloride diffusion. Comput. Concr. 2015, 15, 589-606. [CrossRef]

69. Pack, S.W.; Jung, M.S.; Song, H.W.; Kim, S.H.; Ann, K.Y. Prediction of time dependent chloride transport in concrete structures exposed to a marine environment. Cem. Concr. Res. 2010, 40, 302-312. [CrossRef]

70. Song, H.W.; Lee, C.H.; Ann, K.Y. Factors influencing chloride transport in concrete structures exposed to marine environments. Cem. Concr. Compos. 2008, 30, 113-121. [CrossRef]

71. Lindvall, A. Environmental Actions on Concrete Exposed in Marine and Road Environments and Its Response. Ph.D. Thesis, Chalmers University of Technology, Gothenburg, Sweden, 2003.

72. Poulsen, E.; Mejlbro, L. Diffusion of Chloride in Concrete: Theory and Application; CRC Press: Boca Raton, FL, USA, 2005.

73. Thomas, M.D.A. Chloride diffusion in high-performance lightweight aggregate concrete. Symp. Pap. 2006, 234, 797-812. [CrossRef]

74. Ibrahim, M.; Ahmad, A.; Barry, M.S.; Alhems, L.M.; Mohamed Suhoothi, A.C. Durability of Structural Lightweight Concrete Containing Expanded Perlite Aggregate. Int. J. Concr. Struct. Mater. 2020, 14. [CrossRef]

75. Liu, X.; Chia, K.S.; Zhang, M.H. Development of lightweight concrete with high resistance to water and chloride-ion penetration. Cem. Concr. Compos. 2010, 32, 757-766. [CrossRef]

76. Helland, S. Performance of lightweight aggregate concrete in marine environment. In Proceedings of the Theodore Bremner Symposium on High-performance Lightweight Concrete as a part of the Sixth CANMET/ACI International Conference on Durability of Concrete, Thessaloniki, Greece, 1-7 June 2003. 